\title{
Cometary Isotopic Measurements
}

\author{
Dominique Bockelée-Morvan ${ }^{1}$ - Ursina Calmonte ${ }^{2} \cdot$ Steven Charnley $^{3} \cdot$ Jean Duprat $^{4}$. \\ Cécile Engrand $^{4}$ - Adeline Gicquel ${ }^{5}$ - Myrtha Hässig ${ }^{6}$ Emmanuël Jehin ${ }^{7}$. \\ Hideyo Kawakita ${ }^{8}$ - Bernard Marty ${ }^{9}$ Stefanie Milam ${ }^{3}$ - Andrew Morse ${ }^{10}$. \\ Philippe Rousselot $^{11}$ - Simon Sheridan ${ }^{10}$ - Eva Wirström ${ }^{12}$
}

Received: 11 December 2014 / Accepted: 5 May 2015

(C) Springer Science+Business Media Dordrecht 2015

\begin{abstract}
Isotopic ratios in comets provide keys for the understanding of the origin of cometary material, and the physical and chemical conditions in the early Solar Nebula. We review here measurements acquired on the $\mathrm{D} / \mathrm{H},{ }^{14} \mathrm{~N} /{ }^{15} \mathrm{~N},{ }^{16} \mathrm{O} /{ }^{18} \mathrm{O},{ }^{12} \mathrm{C} /{ }^{13} \mathrm{C}$, and ${ }^{32} \mathrm{~S} /{ }^{34} \mathrm{~S}$ ratios in cometary grains and gases, and discuss their cosmogonic implications. The review includes analyses of potential cometary material available in collections on Earth, recent measurements achieved with the Herschel Space Observatory, large optical telescopes,
\end{abstract}

D. Bockelée-Morvan

dominique.bockelee@obspm.fr

1 Observatoire de Paris, CNRS, UPMC, Université Paris-Diderot, 5 place Jules Janssen, 92195 Meudon, France

2 Physics Institute, Space Research and Planetary Science, University of Bern, Sidlerstrasse 5, 3012 Bern, Switzerland

3 Astrochemistry Laboratory, Code 691 NASA Goddard Space Flight Center Greenbelt, 8800 Greenbelt Rd, Greenbelt, MD 20771, USA

4 Centre de Sciences Nucléaires et de Sciences de la matière (CSNSM), Université Paris-Sud, UMR 8609-CNRS/IN2P3, 91405 Orsay, France

5 Max Planck Institute for Solar System Research, Justus-von-Liebig-Weg 3, 37077 Göttingen, Germany

6 Southwest Research Institute, San Antonio, TX, USA

7 Département d'Astrophysique, de Géophysique et d'Océanographie de Université de Liège, Place du 20 Août 7, 4000 Liège, Belgium

8 Koyama Astronomical Observatory, Kyoto Sangyo Univ., Motoyama, Kamigamo, Kita, Kyoto 603-8555, Japan

9 CRPG-CNRS, Université de Lorraine, 15 Rue Notre Dame des Pauvres, 54500 Vandoeuvre-lès-Nancy, France

10 Space Sciences, The Open University, Walton Hall, Milton Keynes MK7 6AA, UK

11 Observatoire des Sciences de l'Univers THETA, Institut UTINAM-UMR CNRS 6213, University of Franche-Comté, BP 1615, 25010 Besançon Cedex, France

12 Onsala Space Observatory, Chalmers University of Technology, 43992 Onsala, Sweden 
and Rosetta, as well as recent results obtained from models of chemical-dynamical deuterium fractionation in the early solar nebula. Prospects for future measurements are presented.

Keywords Comets · Isotopes

\section{Introduction}

The solar system formed about 4.6 billion years ago from an infall of matter inside a molecular cloud. A wealth of processes happened, involving chemistry, and dynamics at all scales before the solar system reached its present state with its cortege of planets and small bodies (e.g. Ceccarelli et al. 2014; Mandt et al. 2015, this issue). The view that comets are among the most primitive materials in the solar system stems from their primitive element abundances, similar to that of the bulk solar system for most elements (as deduced from analyses of 1P/Halley and 81P/Wild 2 for rock forming elements), and their extraordinary composition richness in elements in the gas phase, which resembles that of interstellar clouds (Jessberger and Kissel 1991; Bockelée-Morvan et al. 2000; Cochran et al. 2015, this issue; Brownlee 2014). Comets formed in the outer skirts of the solar nebula and trapped volatile species formed either in the presolar cloud or in situ. However, the discovery that comets incorporated high-temperature components formed in the neighborhood of the forming Sun, points out to a large diversity of formation conditions for the comet material, which in turn provides constraints on mixing processes in the solar nebula (Brownlee et al. 2006; Bockelée-Morvan et al. 2002; Wooden 2008).

The isotopic abundances are key tracers for reconstructing the origin and history of cometary material. Indeed, isotopic fractionation is sensitive to environmental conditions, such as temperature, density, radiation, and composition. The strongest variations among volatile element isotope ratios are observed for hydrogen. Therefore deuterium fractionation is an Ariadne's thread for understanding the very first steps of solar system formation, starting with the pre-collapse phase to the formation of planetesimals (Ceccarelli et al. 2014). Key information can also be inferred from the large nitrogen isotopic variations observed among solar system objects, although they are still difficult to interpret.

In this chapter, we review isotopic measurements acquired so far on comets, including on dust particles collected by the Stardust mission (Brownlee 2014). Different lines of evidence indicate that samples from comets have been recovered on Earth. Such samples are of uttermost interest since they allow extremely precise elemental, mineralogical and isotopic analyses at different scales down to the nanometer. Hence this review also present isotopic properties of interplanetary dust particles (IDPs) and micrometeorites of probable cometary origin. To put the measurements into context, we summarize recent studies on interstellar deuterium and nitrogen fractionation, initiated by recent measurements in interstellar sources. Finally, we present prospectives for new isotopic measurements in comets, especially with instruments onboard the Rosetta/Philae space mission.

\section{Isotopic Measurements in Cometary Volatiles}

Because of the faint signatures of deuterated species, $\mathrm{D} / \mathrm{H}$ ratios were only obtained in a handful of bright comets. Table 1 lists measurements of the $\mathrm{D} / \mathrm{H}$ ratio in cometary water acquired so far. It is worth remembering that the $\mathrm{D} / \mathrm{H}$ ratio is equal to half the $\mathrm{HDO} / \mathrm{H}_{2} \mathrm{O}$ ratio, because water contains two atoms of hydrogen. 
Table 1 D/H ratios in cometary molecules

\begin{tabular}{|c|c|c|c|c|}
\hline Species & $\begin{array}{l}\text { Parent } \\
\text { molecule }\end{array}$ & $\mathrm{D} / \mathrm{H}$ ratio $^{\mathrm{a}}$ & Comet & Reference \\
\hline \multirow[t]{3}{*}{$\mathrm{H}_{2} \mathrm{DO}^{+}$} & \multirow[t]{3}{*}{$\mathrm{H}_{2} \mathrm{O}$} & $(3.08 \pm 0.5) \times 10^{-4}$ & 1P/Halley & Balsiger et al. (1995) \\
\hline & & $(3.06 \pm 0.34) \times 10^{-4}$ & 1P/Halley & Eberhardt et al. (1995) \\
\hline & & $(2.1 \pm 0.3) \times 10^{-4}$ & 1P/Halley & Brown et al. (2012) \\
\hline \multirow[t]{9}{*}{ HDO } & \multirow[t]{9}{*}{$\mathrm{H}_{2} \mathrm{O}$} & $(2.9 \pm 1.0) \times 10^{-4}$ & C/1996 B2 (Hyakutake) & $\begin{array}{l}\text { Bockelée-Morvan et al. } \\
\text { (1998) }\end{array}$ \\
\hline & & $(3.3 \pm 0.8) \times 10^{-4}$ & C/1995 O1 (Hale-Bopp) & Meier et al. (1998a) \\
\hline & & $(4.09 \pm 1.45) \times 10^{-4}$ & 8P/Tuttle & Villanueva et al. (2009) \\
\hline & & $(1.61 \pm 0.24) \times 10^{-4}$ & 103P/Hartley 2 & Hartogh et al. (2011) \\
\hline & & $(2.06 \pm 0.22) \times 10^{-4}$ & C/2009 P1 (Garradd) & $\begin{array}{l}\text { Bockelée-Morvan et al. } \\
\text { (2012) }\end{array}$ \\
\hline & & $(5.3 \pm 0.7) \times 10^{-4}$ & 67P/Churyumov-Gerasimenko & Altwegg et al. (2014) \\
\hline & & $<2.5 \times 10^{-4 b}$ & 153P/Ikeya-Zhang & Biver et al. (2006) \\
\hline & & $<5.6 \times 10^{-4}$ & C/2007 N3 (Lulin) & Gibb et al. (2012) \\
\hline & & $<2 \times 10^{-4}$ & 45P/Honda-Mrkos-Pajdušáková & Lis et al. (2013) \\
\hline OD & $\mathrm{H}_{2} \mathrm{O}$ & $(2.5 \pm 0.7) \times 10^{-4}$ & C/2002 T7 (LINEAR) & Hutsemékers et al. (2008) \\
\hline $\mathrm{D}$ & $\mathrm{H}_{2} \mathrm{O}$ & $(4.6 \pm 1.4) \times 10^{-4}$ & C/2001 Q4 (NEAT) & Weaver et al. (2008) \\
\hline \multirow[t]{4}{*}{$\mathrm{DCN}$} & \multirow[t]{4}{*}{$\mathrm{HCN}$} & $(2.3 \pm 0.4) \times 10^{-3}$ & C/1995 O1 (Hale-Bopp) & Meier et al. (1998b) \\
\hline & & $(2.3 \pm 0.6) \times 10^{-3}$ & C/1995 O1 (Hale-Bopp) & Crovisier et al. (2004) \\
\hline & & $<1 \times 10^{-2}$ & C/1996 B2 (Hyakutake) & $\begin{array}{l}\text { Bockelée-Morvan et al. } \\
\text { (1998) }\end{array}$ \\
\hline & & $<1 \times 10^{-2}$ & 103P/Hartley 2 & Gicquel et al. (2014) \\
\hline \multirow[t]{2}{*}{$\mathrm{HDCO}$} & \multirow[t]{2}{*}{$\mathrm{H}_{2} \mathrm{CO}$} & $<2 \times 10^{-2}$ & 1P/Halley & Balsiger et al. (1995) \\
\hline & & $<5 \times 10^{-2}$ & C/1995 O1 (Hale-Bopp) & Crovisier et al. (2004) \\
\hline \multirow[t]{5}{*}{$\mathrm{CH}_{3} \mathrm{D}$} & \multirow[t]{5}{*}{$\mathrm{CH}_{4}$} & $<1 \times 10^{-1}$ & 153P/2002 C1 (Ikeya-Zhang) & Kawakita et al. (2003) \\
\hline & & $<1 \times 10^{-2}$ & C/2001 Q4 (NEAT) & Kawakita et al. (2005) \\
\hline & & $<5 \times 10^{-3}$ & C/2004 Q2 (Machholz) & Bonev et al. (2009) \\
\hline & & $<6.4 \times 10^{-3}$ & C/2004 Q2 (Machholz) & $\begin{array}{l}\text { Kawakita and Kobayashi } \\
\text { (2009) }\end{array}$ \\
\hline & & $<7.5 \times 10^{-3}$ & C/2007 N3 (Lulin) & Gibb et al. (2012) \\
\hline $\mathrm{NH}_{2} \mathrm{D}$ & $\mathrm{NH}_{3}$ & $<4 \times 10^{-2}$ & C/1995 O1 (Hale-Bopp) & Crovisier et al. (2004) \\
\hline ND & $\mathrm{NH}_{3}$ & $<6 \times 10^{-3}$ & C/1996 B2 (Hyakutake) & Meier et al. (1998c) \\
\hline \multirow[t]{2}{*}{$\mathrm{CH}_{3} \mathrm{OD}$} & \multirow[t]{2}{*}{$\mathrm{CH}_{3} \mathrm{OH}$} & $<1 \times 10^{-2}$ & 1P/Halley & Eberhardt et al. (1994) \\
\hline & & $<3 \times 10^{-2}$ & C/1995 O1 (Hale-Bopp) & Crovisier et al. (2004) \\
\hline $\mathrm{CH}_{2} \mathrm{DOH}$ & $\mathrm{CH}_{3} \mathrm{OH}$ & $<8 \times 10^{-3}$ & C/1995 O1 (Hale-Bopp) & Crovisier et al. (2004) \\
\hline \multirow[t]{2}{*}{ HDS } & \multirow[t]{2}{*}{$\mathrm{H}_{2} \mathrm{~S}$} & $<2 \times 10^{-1}$ & C/1995 O1 (Hale-Bopp) & Crovisier et al. (2004) \\
\hline & & $<8 \times 10^{-3}$ & 17P/Holmes & Biver et al. (2008) \\
\hline $\mathrm{CD}$ & & $<3 \times 10^{-2}$ & C/1996 B2 (Hyakutake) & Meier et al. (1998c) \\
\hline
\end{tabular}

\footnotetext{
a Value for the parent molecule, except for $\mathrm{ND}$ and $\mathrm{CD}$, where it refers to ND/NH, and $\mathrm{CD} / \mathrm{CH}$ values

${ }^{\mathrm{b}}$ Revised value using updated $\mathrm{H}_{2} \mathrm{O}$ production rates from Biver et al. (2007)
} 


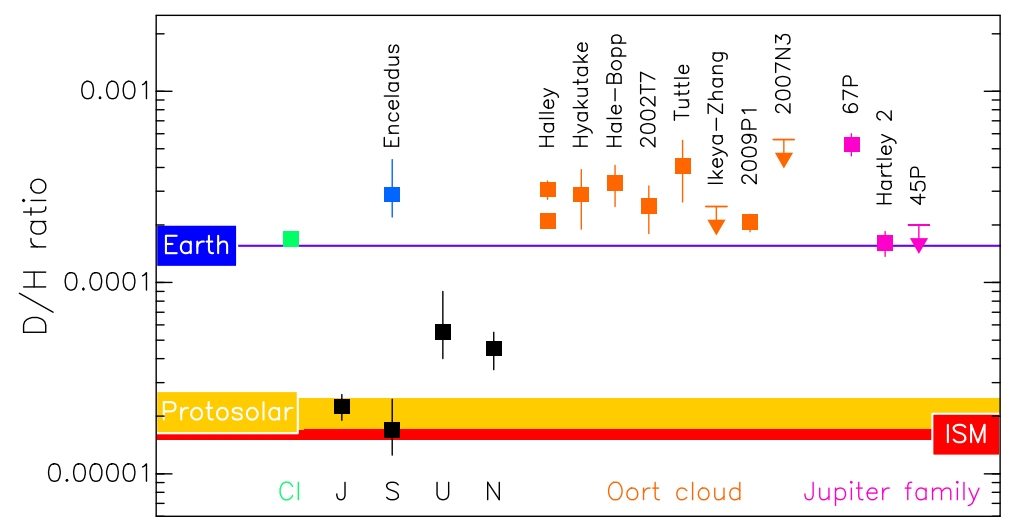

Fig. 1 D/H ratio in the water of comets compared to values in carbonaceous meteorites (CI), Earth's oceans (VSMOW), and Enceladus. Displayed data for planets, the interstellar medium, and the protosolar nebula refer to the value in $\mathrm{H}_{2}$. Adapted from Lis et al. (2013)

\subsection{Deuterium}

\subsubsection{Water}

The first measurements of the $\mathrm{D} / \mathrm{H}$ ratio in cometary $\mathrm{H}_{2} \mathrm{O}$ were obtained in comet $1 \mathrm{P} / \mathrm{Halley}$ from mass-resolved ion-spectra of $\mathrm{H}_{3} \mathrm{O}^{+}$acquired with the Ion Mass Spectrometer (IMS) (Balsiger et al. 1995) and the Neutral Mass Spectrometer (NMS) (Eberhardt et al. 1995) instruments onboard the European Giotto spacecraft. These independent data provided a consistent $\mathrm{D} / \mathrm{H}$ value of $\sim 3 \times 10^{-4}$, which corresponds to twice the Vienna Standard Mean Ocean Water VSMOW of $155.76 \pm 0.1 \mathrm{ppm}$ (Table 1, Balsiger et al. 1995; Eberhardt et al. 1995). However, Brown et al. (2012) reexamined the NMS measurements, reevaluating the $\mathrm{D} / \mathrm{H}$ ratio in comet $1 \mathrm{P} /$ Halley to $(2.1 \pm 0.3) \times 10^{-4}$.

From observations undertaken with the Caltech Submillimeter Observatory and the James Clerk Maxwell telescope (JCMT), HDO was detected in the bright long-period comets C/1996 B2 (Hyakutake) and C/1995 O1 (Hale-Bopp) from its $1_{01}-0_{00}$ line at 464.925 GHz (Bockelée-Morvan et al. 1998; Meier et al. 1998a). The derived D/H values in these two comets are in agreement with the determinations in comet Halley (Table 1, Fig. 1). However, observations of the HDO $1_{10}-1_{01}$ transition at $509.292 \mathrm{GHz}$ in the Halleytype comet $153 \mathrm{P} /$ Ikeya-Zhang yielded $\mathrm{D} / \mathrm{H}<2.5 \times 10^{-4}$, suggesting for the first time an hydrogen isotopic diversity in the Oort-cloud population (Biver et al. 2006).

Using the new high resolution Cryogenic Infrared Echelle Spectrograph (CRIRES) of the Very Large Telescope (VLT), Villanueva et al. (2009) observed in early 2008 the HDO ro-vibrational transitions near $3.7 \mu \mathrm{m}$ in the Halley-family comet 8P/Tuttle originating from the Oort cloud. Twenty three lines were co-added to get a marginal detection of HDO, from which a formal value of $\mathrm{D} / \mathrm{H}$ of $(4.09 \pm 1.45) \times 10^{-4}$ was derived.

In cometary atmospheres, water photodissociates into mainly $\mathrm{OH}$ and $\mathrm{H}$. The $\mathrm{OD} / \mathrm{OH}$ ratio was measured to be $(2.5 \pm 0.7) \times 10^{-4}$ in the Oort-Cloud comet C/2002 T7 (LINEAR) through ground-based observations of the $\mathrm{OH} \mathrm{A}{ }^{2} \Sigma^{+}-\mathrm{X}^{2} \Pi_{i}$ ultraviolet bands at $310 \mathrm{~nm}$ obtained with the VLT feeding the Ultraviolet-Visual Echelle Spectrograph (UVES) (Hutsemékers et al. 2008). No individual OD line was detected, but a marginal $3 \sigma$ detection of OD was obtained by co-adding the brightest lines. Atomic deuterium (D) emission was also 
discovered during ultraviolet observations of comet C/2001 Q4 (NEAT) in April 2004 using the Space Telescope Imaging Spectrograph (STIS) of the Hubble Space Telescope (Weaver et al. 2008). The Lyman- $\alpha$ emission from both $\mathrm{D}$ and atomic hydrogen were detected, from which a preliminary value $\mathrm{D} / \mathrm{H}=(4.6 \pm 1.4) \times 10^{-4}$ was derived, assuming that $\mathrm{H}_{2} \mathrm{O}$ is the dominant source of the observed $\mathrm{D}$ and $\mathrm{H}$, as it is likely the case. The strength of the optical method is that both normal and rare isotopologues have lines in the same spectral interval and are observed simultaneously, avoiding problems related to comet variable activity.

The most recent spectroscopic D/H measurements in cometary water were acquired using the ESA Herschel space observatory. The HDO $1_{10}-1_{01}$ transition at $509.292 \mathrm{GHz}$ was observed using the Heterodyne Instrument for the Far-Infrared (HIFI) in the Jupiter-family comets 103P/Hartley 2 and 45P/Honda-Mrkos-Pajdušáková (Hartogh et al. 2011; Lis et al. 2013), and in the Oort-cloud comet C/2009 P1 (Garradd) (Bockelée-Morvan et al. 2012). Observations of HDO were interleaved with observations of the $\mathrm{H}_{2} \mathrm{O}$ and $\mathrm{H}_{2}^{18} \mathrm{O} 1_{10}-1_{01}$ lines. Since the $\mathrm{H}_{2} \mathrm{O}$ ground state rotational lines in comets are optically thick, optically thin lines of $\mathrm{H}_{2}^{18} \mathrm{O}$ provide, in principle, a more reliable reference for the $\mathrm{D} / \mathrm{H}$ determination. The $\mathrm{HDO} / \mathrm{H}_{2}^{18} \mathrm{O}$ was measured to be $0.161 \pm 0.017$ for comet Hartley 2, i.e., consistent with the VSMOW value for this ratio of $0.1554 \pm 0.0001$. The $\mathrm{HDO} / \mathrm{H}_{2}^{18} \mathrm{O}$ value of $0.215 \pm 0.023$ for comet Garradd suggests a significant difference (3- $\sigma$ ) in deuterium content between the comet Garradd and Hartley 2. Hartogh et al. (2011) derived a D/H ratio of $(1.61 \pm 0.24) \times 10^{-4}$ for comet Hartley, assuming an $\mathrm{H}_{2}^{16} \mathrm{O} / \mathrm{H}_{2}^{18} \mathrm{O}$ ratio of $500 \pm 50$ which encompasses the VSMOW value and values measured in cometary water (Jehin et al. 2009, see Sect. 2.3). For comet Garradd, the derived $\mathrm{D} / \mathrm{H}$ ratio is $(2.06 \pm 0.22) \times 10^{-4}$ based on the $\mathrm{HDO} / \mathrm{H}_{2}^{16} \mathrm{O}$ production rate ratio, and $(2.15 \pm 0.32) \times 10^{-4}$, using the same method as Hartogh et al. (2011). Herschel observations in the Jupiter family comet 45P/Honda-MrkosPajdušáková were unsuccessful in detecting the HDO $509 \mathrm{GHz}$ line, but resulted in a $3 \sigma$ upper limit for the $\mathrm{D} / \mathrm{H}$ ratio of $2.0 \times 10^{-4}$ which is consistent with the value measured in comet 103P/Hartley 2 and excludes the canonical pre-Herschel value measured in Oortcloud comets of $\sim 3 \times 10^{-4}$ at the $4.5 \sigma$ level (Lis et al. 2013).

Whereas the Herschel measurements were suggesting a Earth-like value for Jupiter family comets, the ROSINA mass-spectrometer onboard Rosetta (Balsiger et al. 2007) measured in comet $67 \mathrm{P} /$ Churymov-Gerasimenko a $\mathrm{D} / \mathrm{H}$ value of $(5.3 \pm 0.7) \times 10^{-4}$, i.e., more than three times the VSMOW value (Altwegg et al. 2014).

\subsection{2 $\mathrm{HCN}$}

The first detection of DCN (J:5-4; $362.046 \mathrm{GHz}$ ) was obtained by Meier et al. (1998b) in the bright Oort comet C/1995 O1 (Hale-Bopp) using the JCMT, where a D/H ratio of $(2.3 \pm 0.4) \times 10^{-3}$ was derived. Crovisier et al. (2004) obtained a marginal $3 \sigma$ detection of DCN (J:2-1; $217.2385 \mathrm{GHz})$ with the IRAM 30m telescope toward the same comet and reported a D/H ratio consistent with Meier et al. (1998b). The deuterium enrichment in $\mathrm{HCN}$ is 7 times larger than that measured in $\mathrm{H}_{2} \mathrm{O}$ in comet Hale-Bopp and most Oort cloud comets. (Sect. 2.1.1).

Bockelée-Morvan et al. (1998) derived a $3 \sigma$ upper limit of DCN (J:5-4; 362.046 GHz) in the bright long-period comet C/1996 (Hyakutake) by using the $10.4 \mathrm{~m}$ Leighton telescope of the Caltech Submillimeter Observatory (CSO). They obtained a D/H $<1.0 \times 10^{-2}$. Gicquel et al. (2014) measured for the first time an upper limit for DCN (J:4-3; 362.0465 GHz) in a Jupiter-Family comet (103P/Hartley 2$)$ using the JCMT. They concluded to a D/H ratio < $1.0 \times 10^{-2}$. Blake et al. (1999) deduced a larger $\mathrm{D} / \mathrm{H}$ ratio in jets from interferometric radio data, which might suggest variations in the coma. The $(\mathrm{D} / \mathrm{H})_{\mathrm{HCN}}$ ratios deduced from single-dish observations are summarized in Table 1. 
By comparison, a range of $(0.4-7.0) \times 10^{-2}$ for the $\mathrm{DCN} / \mathrm{HCN}$ ratio was determined in the interstellar medium (ISM) (Roberts et al. 2002; Jørgensen et al. 2004). The low $\mathrm{DCN} / \mathrm{HCN}$ value in comets compared to the ISM can suggest some reprocessing in the Solar Nebula that occurred before the incorporation of these molecules into comets (Mousis et al. 2000), as it will be discussed in depth in Sect. 4.2. Alternatively, the D/H ratios in both water and $\mathrm{HCN}$ in comet Hale-Bopp may reflect an ion-chemistry at about 30-35 K which took place either in the presolar cloud or in the outer regions of the solar nebula (Meier et al. 1998b).

\subsection{3 $\mathrm{CH}_{4}$}

Because methane has four identical $\mathrm{H}$-atoms to be substituted with deuterium, the abundance ratio of singly deuterated methane $\left(\mathrm{CH}_{3} \mathrm{D}\right)$ relative to $\mathrm{CH}_{4}$ is enhanced, i.e., $\mathrm{D} / \mathrm{H}=0.25 \times$ $\left(\mathrm{CH}_{3} \mathrm{D} / \mathrm{CH}_{4}\right)$.

Constraints on the $\mathrm{D} / \mathrm{H}$ ratio in methane were obtained from observations of vibrational bands in the near-IR. The strongest vibrational band of $\mathrm{CH}_{3} \mathrm{D}$ in cometary atmospheres is the $v_{4}$ band around $3000 \mathrm{~cm}^{-1}$, which is close to the $v_{3}$ vibrational band of $\mathrm{CH}_{4}$. They are close to each other and this situation allows us to measure emission lines of $\mathrm{CH}_{4}$ and $\mathrm{CH}_{3} \mathrm{D}$ simultaneously.

The first trial to detect $\mathrm{CH}_{3} \mathrm{D}$ in comet 153P/Ikeya-Zhang provided a $2 \sigma$ upper limit for the $\mathrm{D} / \mathrm{H}$ ratio of 0.075 (Kawakita and Watanabe 2003). A more stringent upper limit of 0.01 was later reported in comet C/2001 Q4 (NEAT) (Kawakita et al. 2005). In comet C/2004 Q2 (Machholz), $3 \sigma$ upper limits of 0.003 and 0.005 were reported by Kawakita and Kobayashi (2009) and Bonev et al. (2009), respectively. More recently, Gibb et al. (2012) derived $\mathrm{D} / \mathrm{H}<0.007(3 \sigma)$ in comet $\mathrm{C} / 2007 \mathrm{~N} 3$ (Lulin).

Chemical network models for low temperature environments (e.g., Aikawa and Herbst 1999) predict large $\mathrm{CH}_{3} \mathrm{D} / \mathrm{CH}_{4}$ abundance ratios, up to $0.1-0.2$ at $10 \mathrm{~K}$ (i.e, $\mathrm{D} / \mathrm{H}$ up to 0.025-0.05). Upper limits measured in comets cannot be explained by methane deuteration at such low temperatures.

\subsubsection{Other Molecules}

Some constraints on the level of deuteration in other cometary molecules have been obtained. Using Hale-Bopp data in the millimeter range, Crovisier et al. (2004) obtained D/H upper limits for $\mathrm{NH}_{3}, \mathrm{H}_{2} \mathrm{CO}$, and $\mathrm{CH}_{3} \mathrm{OH}$ (both $\mathrm{CH}_{3} \mathrm{OD}$, and $\mathrm{CH}_{3} \mathrm{DOH}$ ), which range typically from 0.01 to 0.05 . An upper limit of $\mathrm{D} / \mathrm{H}<0.008$ was obtained for $\mathrm{H}_{2} \mathrm{~S}$ in comet 17P/Holmes (Biver et al. 2008). Measurements for some of these molecules will be possible from Rosetta (see Sect. 5.1 and Table 6), or will need to await for a very bright comet observed with ALMA (see Sect. 5.2).

\subsection{Nitrogen}

Figure 2 summarizes nitrogen isotopic ratios measured in comets, and how they compare to values measured in other primitive Solar System materials.

\subsubsection{HCN and CN}

The nitrogen isotopic ratio ${ }^{14} \mathrm{~N} /{ }^{15} \mathrm{~N}$ was measured for the first time in comet $\mathrm{C} / 1995 \mathrm{O} 1$ (Hale-Bopp) in 1997 in $\mathrm{HCN}$ as well as in the $\mathrm{CN}$ violet band. The ${ }^{14} \mathrm{~N} /{ }^{15} \mathrm{~N}$ values derived from the HCN emission at sub-millimetre range (323 \pm 46 , Jewitt et al. 1997; $330 \pm 98$ 
Table 2 Isotopic ratios in comets: Carbon, oxygen, nitrogen and sulfur

\begin{tabular}{|c|c|c|c|c|}
\hline Isotopic ratio & Species & Value & Comet & References \\
\hline \multirow[t]{9}{*}{${ }^{12} \mathrm{C} /{ }^{13} \mathrm{C}$} & \multirow[t]{4}{*}[\mathrm{C}_{2}]{} & $93 \pm 10$ & 4 comets & Wyckoff et al. (2000) \\
\hline & & $85 \pm 20$ & $\mathrm{C} / 2002 \mathrm{~T} 7$ & Rousselot et al. (2012) \\
\hline & & $80 \pm 20$ & $\mathrm{C} / 2001 \mathrm{Q} 4$ & Rousselot et al. (2012) \\
\hline & & $94 \pm 33$ & $\mathrm{C} / 2012 \mathrm{~S} 1$ & Shinnaka et al. (2014a) \\
\hline & \multirow[t]{3}{*}[\mathrm{CN}]{} & $91 \pm 4$ & 21 comets & Manfroid et al. (2009) \\
\hline & & $95 \pm 15$ & 103P/Hartley 2 & Jehin et al. (2011) \\
\hline & & $95 \pm 25$ & $\mathrm{C} / 2012 \mathrm{~F} 6$ & Decock et al. (2014) \\
\hline & \multirow[t]{2}{*}[\mathrm{HCN}]{} & $111 \pm 12$ & C/1995 O1 & Jewitt et al. (1997) \\
\hline & & $114 \pm 26$ & 17P/Holmes & Bockelée-Morvan et al. (2008) \\
\hline \multirow[t]{9}{*}{${ }^{14} \mathrm{~N} /{ }^{15} \mathrm{~N}$} & \multirow[t]{2}{*}[\mathrm{HCN}]{} & $205 \pm 70$ & C/1995 O1 & Bockelée-Morvan et al. (2008) \\
\hline & & $139 \pm 26$ & 17P/Holmes & Bockelée-Morvan et al. (2008) \\
\hline & \multirow[t]{4}{*}[\mathrm{CN}]{} & $141 \pm 29$ & 21 comets & Manfroid et al. (2009) \\
\hline & & $220 \pm 40$ & 73P (fragment C) & Manfroid et al. (2009) \\
\hline & & $165 \pm 40$ & 17P/Holmes & Bockelée-Morvan et al. (2008) \\
\hline & & $155 \pm 25$ & 103P/Hartley 2 & Jehin et al. (2011) \\
\hline & \multirow[t]{3}{*}[\mathrm{NH}_{2}]{} & $90-190$ & 12 comets & Rousselot et al. (2014) \\
\hline & & $139 \pm 38$ & $\mathrm{C} / 2012 \mathrm{~S} 1$ & Shinnaka et al. (2014b) \\
\hline & & $140 \pm 30$ & $\mathrm{C} / 2012 \mathrm{~F} 6$ & Decock et al. (2014) \\
\hline \multirow[t]{6}{*}{${ }^{16} \mathrm{O} /{ }^{18} \mathrm{O}$} & \multirow[t]{6}{*}[\mathrm{H}_{2}\mathrm{O}]{} & $518 \pm 45$ & 1P/Halley & Balsiger et al. (1995) \\
\hline & & $470 \pm 40$ & 1P/Halley & Eberhardt et al. (1995) \\
\hline & & $530 \pm 60$ & 4 comets & Biver et al. (2007) \\
\hline & & $425 \pm 55$ & $\mathrm{C} / 2002 \mathrm{~T} 7$ & Hutsemékers et al. (2008) \\
\hline & & $300 \pm 150$ & $\mathrm{C} / 2012 \mathrm{~F} 6$ & Decock et al. (2014) \\
\hline & & $523 \pm 32$ & $\mathrm{C} / 2009 \mathrm{P} 1$ & Bockelée-Morvan et al. (2012) \\
\hline \multirow[t]{4}{*}{${ }^{32} \mathrm{~S} /{ }^{34} \mathrm{~S}$} & {$[\mathrm{CS}]$} & $27 \pm 3$ & C/1995 O1 & Jewitt et al. (1997) \\
\hline & {$[\mathrm{CS}]$} & $16 \pm 3$ & 17P/Holmes & Biver et al. (2008) \\
\hline & {$\left[\mathrm{S}^{+}\right]$} & $23 \pm 6$ & 1P/Halley & Altwegg (1996) \\
\hline & {$\left[\mathrm{H}_{2} \mathrm{~S}\right]$} & $16 \pm 3$ & $\mathrm{C} / 1995 \mathrm{O} 1$ & Crovisier et al. (2004) \\
\hline
\end{tabular}

Ziurys et al. 1999), were consistent with the telluric value (272, Anders and Grevesse 1989) while the ratio derived from optical high resolution spectroscopy of CN ( $140 \pm 35$, Arpigny et al. 2003) was widely discordant. Subsequent observations of a dozen comets of various origins lead to ${ }^{14} \mathrm{~N} /{ }^{15} \mathrm{~N}=147.8 \pm 5.7$ from CN (Jehin et al. 2009). The discrepancy between $\mathrm{CN}$ and $\mathrm{HCN}$, a presumed parent, was eventually solved with the quasi simultaneous sub-millimeter and optical observations of $\mathrm{HCN}$ and $\mathrm{CN}$ in comet $17 \mathrm{P} / \mathrm{Holmes}$ performed a couple of days after its huge and bright outburst in October 2007 (Bockelée-Morvan et al. 2008). The nitrogen isotopic ratios derived from the two techniques are found in agreement with each other and with the values found in other comets. The reanalysis of the Hale-Bopp sub-millimeter data (Bockelée-Morvan et al. 2008) also gave much lower values for the nitrogen ratio and established that $\mathrm{HCN}$ has most probably the same non-terrestrial nitrogen isotopic composition as $\mathrm{CN}$. No other measurements in $\mathrm{HCN}$ have been made due to the difficulty of detection of the faint $\mathrm{HC}^{15} \mathrm{~N}$ lines in the radio range but the $\mathrm{CN}$ bright violet band $(0,0)$ at $3880 \AA$ was observed in about 20 comets since Hale-Bopp with high resolution optical spectrometers like the Ultraviolet and Visual Echelle Spectrograph (UVES) mounted at the ESO Very Large Telescope (VLT), the High Resolution Echelle Spectrometer 


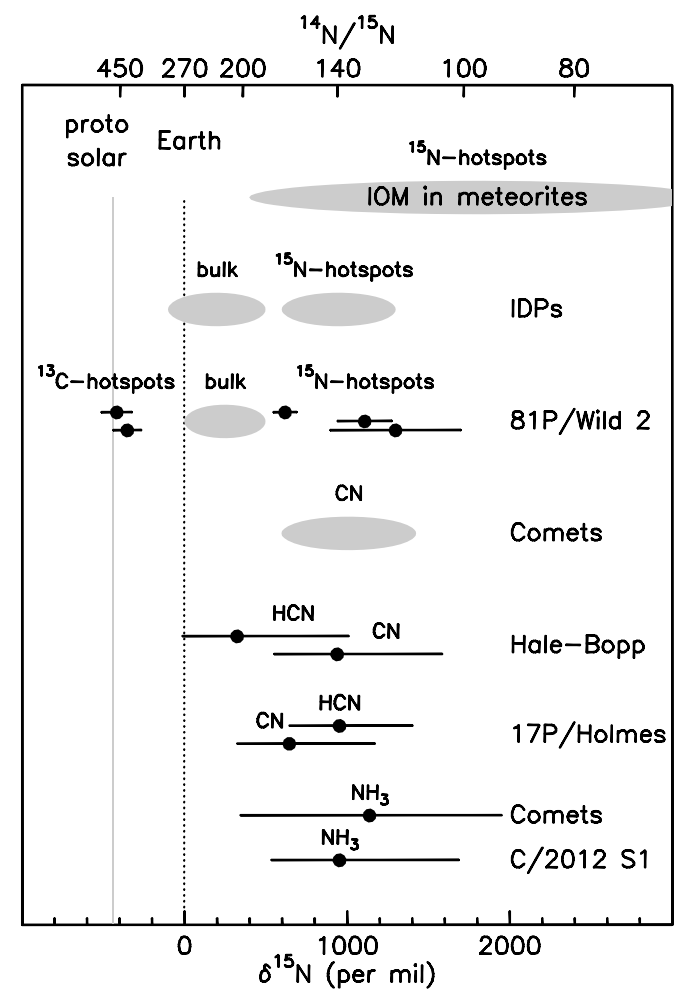

Fig. $2 \mathrm{~N}$ isotope measurements in primitive matter of the Solar System, given either as ${ }^{14} \mathrm{~N} /{ }^{15} \mathrm{~N}$ ratios or $\delta^{15} \mathrm{~N}$ values $\left(\delta^{15} \mathrm{~N}=\left({ }^{14} \mathrm{~N} /{ }^{15} \mathrm{~N}\right) /\left({ }^{14} \mathrm{~N} /{ }^{15} \mathrm{~N}\right)\right.$ Earth -1$)$. Shown are the protosolar value measured by the Genesis mission (Marty et al. 2011), values in $\mathrm{HCN}$ and $\mathrm{CN}$ for comet 17P/Holmes (Bockelée-Morvan et al. 2008), comet Hale-Bopp (Arpigny et al. 2003; Bockelée-Morvan et al. 2008) and other comets (Jehin et al. 2009), in $\mathrm{NH}_{3}$ from $\mathrm{NH}_{2}$ observations (Rousselot et al. 2014; Shinnaka et al. 2014b), in dust particles of comet 81P/Wild 2 collected by the Stardust mission (McKeegan et al. 2006), in interplanetary dust particles IDPs (Floss et al. 2006), and in the insoluble organic matter (IOM) in carbonaceous meteorites (Busemann et al. 2006). So-called hotspots are regions that present strong isotopic enrichments relative to the surrounding material. ${ }^{13} \mathrm{C}$ hotspots refer to $81 \mathrm{P} /$ Wild 2 submicrometre grains enriched in ${ }^{13} \mathrm{C}$ with respect to the terrestrial ${ }^{12} \mathrm{C} /{ }^{13} \mathrm{C}$ ratio and depleted in ${ }^{15} \mathrm{~N}$. Points with error bars correspond to single measurements. When many measurements are available, ellipses encompassing the range of measured values are drawn. Adapted from Bockelée-Morvan (2011)

(HIRES) at Keck, the High Dispersion Spectrograph (HDS) at Subaru and the 2D Coudé at the Harlan telescope at the McDonald Observatory (Table 2). They provided measurements of ${ }^{14} \mathrm{~N} /{ }^{15} \mathrm{~N}$ for comets of various origins (new Oort-cloud comets, Halley type comets, and Jupiter family comets), for comets at various heliocentric distances (from 0.6 AU to $3.7 \mathrm{AU}$ ), at different distances from the nucleus, during comet outbursts or splitting events (Jehin et al. 2004; Manfroid et al. 2005; Hutsemékers et al. 2005; Jehin et al. 2006, 2008, 2009; Manfroid et al. 2009; Jehin et al. 2011; Decock et al. 2014). All the measurements are providing the same value for the nitrogen ratio within the errors but one comet, the carbon poor and split comet 73P/Schwassmann-Wachmann 3 (Jehin et al. 2008; Shinnaka et al. 2011). Whilst the value for the ${ }^{12} \mathrm{C} /{ }^{13} \mathrm{C}$ ratio (see Sect. 2.3.1), derived from $\mathrm{C}_{2}, \mathrm{CN}$ and $\mathrm{HCN}$, is in very good agreement with the solar and terrestrial value of 89 , the nitrogen isotopic ratio, derived from $\mathrm{CN}$ and $\mathrm{HCN}$, is very different from the telluric value of 272 . The large ${ }^{15} \mathrm{~N}$ excess in 
cometary volatiles relative to the Earth atmospheric value indicates that $\mathrm{N}$-bearing volatiles in the solar nebula underwent important nitrogen isotopic fractionation at some stage of the Solar System formation or earlier in the proto-solar cloud (Rodgers and Charnley 2008).

\subsection{2 $\mathrm{NH}_{3}$}

Ammonia molecules represent typically a little bit less than about $1 \%$ (relative to water) of the molecules observed in cometary coma (e.g. Biver et al. 2012), only about ten molecules have a similar or higher abundance. Photolysis of ammonia by solar UV radiation in the coma produces the $\mathrm{NH}_{2}$ radical with $95 \%$ efficiency (Huebner et al. 1992). This radical has a long lifetime against photodissociation and has many emission lines in the optical wavelength range.

Direct measurement of the ${ }^{14} \mathrm{~N} /{ }^{15} \mathrm{~N}$ isotopic ratio in ammonia, through inversion (in radio), rotational (submillimetre), or vibrational (near-infrared) transitions, are usually difficult due to a lack of sensitivity for the ${ }^{15} \mathrm{NH}_{3}$ detection at the available facilities. Indirect measurement of the ${ }^{14} \mathrm{~N} /{ }^{15} \mathrm{~N}$ isotopic ratio in ammonia, however, can be done by using $\mathrm{NH}_{2}$ emission lines in the optical range because these lines have a strong intensity and are easy to observe in this spectral range. The main problem for doing such a measurement has been, for a long time, the lack of accurate wavelengths measurements. Up to recently only one paper had been published mentioning isotope shifts between ${ }^{14} \mathrm{NH}_{2}$ and ${ }^{15} \mathrm{NH}_{2}$ (Dressler and Ramsay 1959) but this shift was presented in a general plot that was by far not accurate enough for searching for the faint ${ }^{15} \mathrm{NH}_{2}$ emission lines.

To efficiently search for these lines it was necessary to perform new laboratory experiments. Such experiments have been conducted in the Advanced Infrared Line Exploited for Spectroscopy (AILES) of synchrotron SOLEIL (Source Optimisé de Lumière d'Energie Intermédiaire du LURE) and permitted us to establish a list of wavelengths for ${ }^{15} \mathrm{NH}_{2}$ emission lines accurate to about $0.01 \AA$ for the $((0,10,0)-(0,0,0))$ and $((0,9,0)-(0,0,0))$ bands of the $\tilde{A}^{2} A_{1}-\tilde{X}^{2} B_{1}$ system. These wavelengths led to the first clear detection of ${ }^{15} \mathrm{NH}_{2}$ in comets by Rousselot et al. (2014) made by combining spectra of 12 comets taken by the UVES spectrograph at the 8 -m ESO Very Large Telescope $(\lambda / \Delta \lambda \simeq 80000)$ located in Chile. The inferred ${ }^{14} \mathrm{~N} /{ }^{15} \mathrm{~N}$ ratio is 127 in ammonia (in the range $90-190$ taking into account uncertainties).

This work assumed two reasonable assumptions: (i) a similar photodissociation efficiency for ${ }^{14} \mathrm{NH}_{3}$ and ${ }^{15} \mathrm{NH}_{3}$ to produce, respectively, ${ }^{14} \mathrm{NH}_{2}$ and ${ }^{15} \mathrm{NH}_{2}$ radicals, (ii) similar transition probabilities for both ${ }^{14} \mathrm{NH}_{2}$ and ${ }^{15} \mathrm{NH}_{2}$. For the second point the average of many spectra obtained at different heliocentric velocities, i.e. with different Doppler shifts with respect to the solar absorption lines, avoided the issue (in the absence of a complete fluorescence modelling) of being affected by the Swing effects and helped to provide a more robust measurement.

Immediately after the first report another measurement was published, based on a highresolution $(\lambda / \Delta \lambda=72000)$ spectrum obtained on comet C/2012 S1 (ISON) with the 8-m SUBARU telescope and the High Dispersion Spectrograph (Shinnaka et al. 2014b). The measured value of ${ }^{14} \mathrm{~N} /{ }^{15} \mathrm{~N}=139 \pm 38$ is consistent with the previous measurement, and confirms that ammonia in comets is highly fractionated in ${ }^{15} \mathrm{~N}$, comparably to $\mathrm{CN}$ and $\mathrm{HCN}$.

\subsection{Carbon, Oxygen, and Sulfur}

\subsubsection{Carbon}

There are two stable carbon isotopes: ${ }^{12} \mathrm{C}$ and ${ }^{13} \mathrm{C}$. The ratio ${ }^{12} \mathrm{C} /{ }^{13} \mathrm{C}$ has been measured in different solar system objects. The terrestrial value is 89 and is similar to the one detected 
in other solar system objects, such as the Sun, Venus, the Moon, Mars, Jupiter, Saturn, Titan, Neptune, meteorites or the IDPs (Woods and Willacy 2009). This ratio is larger than the value of $\sim 68$ measured in the local interstellar medium, that may result from a ${ }^{13} \mathrm{C}$ enrichment since the formation of the Solar System (Milam et al. 2005).

For comets, historically the first ${ }^{12} \mathrm{C} /{ }^{13} \mathrm{C}$ ratio determinations were obtained from the ${ }^{12} \mathrm{C}^{13} \mathrm{C}$ emission spectrum in the optical range for four bright comets: Ikeya $1963 \mathrm{I}$ (Stawikowski and Greenstein 1964), Tago-Sato-Kosaka 1969 IX (Owen 1973), Kohoutek 1973 XII (Danks et al. 1974), and Kobayashi-Berger-Milon 1975 IX (unpublished data from Lambert and Danks mentioned by Lambert and Danks 1983; Vanysek 1977; Wyckoff et al. 2000). The emission lines used for theses measurements, that belong to the $(1,0)$ Swan bands, are strongly blended with $\mathrm{NH}_{2}$ emission lines. For this reason the $\mathrm{CN}$ B-X $(0,0)$ band was later favored for measuring the ${ }^{12} \mathrm{C} /{ }^{13} \mathrm{C}$ ratio. It has been used for the first time for comet 1P/Halley (Wyckoff and Wehinger 1988; Wyckoff et al. 1989; Kleine et al. 1995). Since then the CN B-X $(0,0)$ band has been used with success for measuring the ${ }^{12} \mathrm{C} /{ }^{13} \mathrm{C}$ ratio in many comets of different origins, with an average ratio of $91.0 \pm 3.6$ (Manfroid et al. 2009). Recently emission lines of the $(2,1)$ and $(1,0)$ bandheads of ${ }^{12} \mathrm{C}^{13} \mathrm{C}$ have been used to measure the ${ }^{12} \mathrm{C} /{ }^{13} \mathrm{C}$ ratio in comets $\mathrm{C} / 2002 \mathrm{~T} 7$ (LINEAR) and $\mathrm{C} / 2001 \mathrm{Q} 4$ (NEAT) (Rousselot et al. 2012).

Some other determinations of the ${ }^{12} \mathrm{C} /{ }^{13} \mathrm{C}$ ratio have been performed with radio spectroscopy of $\mathrm{H}^{13} \mathrm{CN}$. These measurements have been performed for comets $\mathrm{C} / 1995 \mathrm{O} 1$ (HaleBopp) (Jewitt et al. 1997; Ziurys et al. 1999; Bockelée-Morvan et al. 2008) and 17P/Holmes (Bockelée-Morvan et al. 2008). All determinations are consistent with the terrestrial value. Measurements made in the dust samples collected by the Stardust spacecraft are presented in Sect. 3.

\subsubsection{Oxygen}

The first value of the oxygen isotopic ratio in a comet was obtained by the in-situ measurements aboard the Giotto spacecraft and gave ${ }^{16} \mathrm{O} /{ }^{18} \mathrm{O}=495 \pm 37$ for $\mathrm{H}_{3} \mathrm{O}^{+}$in comet 1P/Halley (Eberhardt et al. 1995; Balsiger et al. 1995). Seventeen years after the Giotto flyby, a deep integration spectrum of the bright comet 153P/2002 C1 (Ikeya-Zhang) with the sub-millimeter satellite Odin led to the detection of the $\mathrm{H}_{2}^{18} \mathrm{O}$ line at $548 \mathrm{GHz}$ (Lecacheux et al. 2003). Subsequent observations resulted in the determination of ${ }^{16} \mathrm{O} /{ }^{18} \mathrm{O}=530 \pm 60$, $530 \pm 60,550 \pm 75$ and $508 \pm 33$ in the Oort cloud comets Ikeya-Zhang, C/2001 Q4, C/2002 $\mathrm{T} 7$ and C/2004 Q2 respectively (Biver et al. 2007). Within the error bars, all these measurements are consistent with Halley and the terrestrial value $\left({ }^{16} \mathrm{O} /{ }^{18} \mathrm{O}_{\mathrm{Vsmow}}=499\right)$, although marginally higher.

A few ${ }^{18} \mathrm{OH}$ lines belonging to the ultraviolet $\mathrm{OH}$ system at $310 \mathrm{~nm}$ were detected in the spectra of the bright comets C/2002 T7 (LINEAR) and C/2012 F6 (Lemmon) with UVES at the ESO VLT and allowed for the first time the determination of the ${ }^{16} \mathrm{O} /{ }^{18} \mathrm{O}$ ratio from ground-based observations. From the ${ }^{16} \mathrm{OH} /{ }^{18} \mathrm{OH}$ ratio, ${ }^{16} \mathrm{O} /{ }^{18} \mathrm{O}=425 \pm 55$ and $350 \pm 150$ were derived respectively (Hutsemékers et al. 2008; Decock et al. 2014). These values are equal, within the uncertainties, to the terrestrial value and to the ratio measured in other comets, although marginally smaller. An enrichment of ${ }^{18} \mathrm{O}$ in comets has been predicted by some models of the pre-solar nebula by CO self-shielding to explain the so-called"oxygen anomaly" i.e. the fact that oxygen isotope variations in meteorites cannot be explained in any easy way (Yurimoto and Kuramoto 2004). Recently $\mathrm{H}_{2} \mathrm{O}$, and $\mathrm{H}_{2}^{18} \mathrm{O} 1_{10}-1_{01}$ lines were observed with high signal-to-noise ratio in the Oort Cloud comet C/2009 P1 (Garradd) using the HIFI instrument onboard the IR Herschel space telescope (Bockelée-Morvan et al. 2012). The measured oxygen ratio of $523 \pm 32$ is consistent with the terrestrial value. 


\subsubsection{Sulfur}

A few measurements have been acquired for the ${ }^{32} \mathrm{~S} /{ }^{34} \mathrm{~S}$ ratio in cometary gases. The first investigation was made in comet $1 \mathrm{P} /$ Halley through in situ mass spectrometry $\left(\mathrm{S}^{+}\right.$ion, Altwegg 1996). Using millimetre spectroscopy, determinations were made for CS (Jewitt et al. 1997; Biver et al. 2008), a photo-dissociation product of $\mathrm{CS}_{2}$, and for $\mathrm{H}_{2} \mathrm{~S}$ (Crovisier et al. 2004). Inferred values are given in Table 2 . They are consistent within $2 \sigma$ with the terrestrial value of 23 .

\section{Measurements in Cometary Dust and Analogs}

Samples from comets have been identified on Earth. Dust particles directly sampled from comet 81P/Wild 2 have been collected by the Stardust mission and returned to laboratories in 2006. For others, a cometary origin is inferred from different lines of evidence. Such samples provide unique information since extremely precise elemental, mineralogical and isotopic analyses at different scales down to the nanometer permit direct comparison with asteroidal material delivered by meteorites. However, they do not allow access to the composition of ices, because these phases, if any, were lost during processing on parent bodies, during atmospheric entry, or during sampling in the case of Stardust grains.

At least three types of samples with certain to probable cometary origin are available in laboratories:

- The NASA Discovery Stardust mission collected micro-grains of cometary material in the tail of comet 81P/Wild 2 and returned this cometary matter to Earth for laboratory analysis (Brownlee et al. 2006; Brownlee 2014);

- Interplanetary dust particles (IDPs) are small grains collected in the Earth stratosphere by NASA, that have sizes typically below $50 \mu \mathrm{m}$ (Sect. 3.2). Among these particles, a subset, the chondritic-porous anhydrous IDPs, are thought to have a cometary origin.

- Ultracarbonaceous Antartic Micrometeorites (UCAMMs) recovered in Antarctic snow show compositions and stable isotope signatures also consistent with derivation from a cometary reservoir (Sect. 3.3).

Besides these materials for which a cometary origin is beyond doubt or reasonably well constrained, other cosmochemical materials on Earth have been proposed to be cometary in origin, such as some of the volatile-rich carbonaceous chondrites, as first suggested by Anders (1975), and others (e.g. McSween and Weissman 1989; Campins and Swindle 1998; Gounelle et al. 2006; Weisberg and Connolly 2008; Haack et al. 2011). Recently, a piece of carbon-rich material found in Egypt and nicknamed Hypatia has been interpreted as originating from a comet that exploded over Africa $35 \mathrm{Myr}$ ago and made the Lybian glass strewnfield (Kramers et al. 2013).

\subsection{Stardust}

In 2004, NASA Discovery's Stardust mission succeeded in collecting grains from a Jupiterfamily comet (JFC) named 81P/Wild 2, and in returning them to Earth two years later for laboratory analyses (Brownlee et al. 2006; Brownlee 2014). JFCs, a sub-population of the Kuiper belt object (KBO) family, are thought to represent primitive material consisting of silicates, organics and ice that was assembled in the outer solar system and stored beyond 
the orbit of Neptune since 4.5 Gyr. Before 1974, comet 81P/Wild 2 was on a 43 -year orbit that ranged from Jupiter to beyond Uranus. Since then it is on a 6-year orbit crossing the Earth's region. Comet Wild 2 is a particularly active comet with up to 24 jets identified and a water loss estimated at 20000 tons per day. The spacecraft flew within $236 \mathrm{~km}$ of the comet's $4.5 \mathrm{~km}$ diameter nucleus. Cometary grains were collected during a flyby encounter by passive implantation into aerogel, a low-density silica foam, and by impacting onto the aluminum frame (Brownlee et al. 2003, 2004). On January 15th, 2006, the Stardust sample container returned safely to Earth, delivering the first cometary samples for laboratory analysis (Brownlee et al. 2006; Brownlee 2014). Due to the high differential velocity of $6.1 \mathrm{~km} / \mathrm{s}$ between the spacecraft and the comet, cometary grains suffered mass loss and fragmentation during the collection process, to various extents that depended on the nature and density of the grains. While the finest material was mostly severely heated and mixed with the collecting silica aerogel during capture, some of the coarsest grains did not heat up to the melting point, and detailed mineralogical and geochemical analyses down to the nanometer scale revealed the nature of this cometary matter.

Contrary to some expectations, grains collected by Stardust are not dominated by interstellar grains coated with radiation-processed organics. Most of the analyzed materials are isotopically close to chondritic material, and were likely formed by the same set of high temperature processes that led to the formation of constituents of primitive meteorites. As for chondrites, Wild 2 grains contain chondrules, calcium-aluminum rich inclusions, $\mathrm{Mg}$ rich olivines and pyroxenes. In comet Wild 2, such a high temperature material has been assembled with ice, demonstrating that large scale lateral mixing took place in the forming solar system.

There are nevertheless significant differences between comet Wild 2 and volatile-rich meteorites, e.g. carbonaceous chondrites. Organics in Wild 2 material are scarce, and there is little evidence for the occurrence of hydrated material, contrary to hydrous carbonaceous chondrites for which parent body aqueous alteration resulted in the formation of clay minerals and carbonates. It is not clear whether these differences are due to the high speed collection of grains or not. Wild 2 material appears to contain a mix of material more diverse than that found in chondrites, which may also point to a different processing history of cometary bodies compared to asteroids. Below is a summary of the isotopic compositions measured in Stardust material (McKeegan et al. 2006, and references therein).

- Bulk material presents moderate excesses of $\mathrm{D}$ with $\mathrm{D} / \mathrm{H}$ ratios up to a factor of three higher than terrestrial (VSMOW). No hydrated minerals have been identified in Stardust samples, so it is likely that the measured $\mathrm{D} / \mathrm{H}$ values are related to the carbonaceous phases, and are not representative of the $\mathrm{D} / \mathrm{H}$ ratio of water in comet $81 \mathrm{P} /$ Wild 2 . Variations in $\delta \mathrm{D}\left(\delta \mathrm{D}=\left[(\mathrm{D} / \mathrm{H}) /(\mathrm{D} / \mathrm{H})_{\text {VSMOW }}-1\right] \times 1000\right)$ within a particle are also observed with some "hotspots" having a $\delta \mathrm{D}$ up to $2200 \pm 900$ permil. Because of the association with carbon and the lack of evidence for any hydrated minerals in Wild 2 grains, it is unlikely that the $\mathrm{D} / \mathrm{H}$ values are related to cometary water.

- Overall, the ${ }^{13} \mathrm{C} /{ }^{12} \mathrm{C}$ ratio $\left(\delta^{13} \mathrm{C}\right.$ from -20 to -50 permil relative to terrestrial standard $)$ shows moderate variations.

- Likewise, most ${ }^{15} \mathrm{~N} /{ }^{14} \mathrm{~N}$ ratios cluster around the terrestrial value and are also consistent with values found in most meteorites (Stadermann et al. 2008). A few $\delta^{15} \mathrm{~N}$ values range from +100 to +500 permil. So far, excesses of ${ }^{15} \mathrm{~N}$ typical of cometary values (around +800 to +1000 per mil, Sect. 2.2) are not observed in bulk analysis. On a smaller scale, ${ }^{15} \mathrm{~N}$-rich hotspots with a maximum of $\delta^{15} \mathrm{~N}=1300 \pm 400$ permil are observed, similar to the highest values found in refractory organic matter in interplanetary dust particles (IDPs, see Sect. 3.2) and in various types of carbonaceous chondrites (CR, CH-CB and 
CM, Busemann et al. 2006; Briani et al. 2009). Several presolar grains have been identified showing much larger $\mathrm{C}$ and $\mathrm{N}$ isotope variations (from +60 to +964 permil for $\delta^{13} \mathrm{C}$, and from -518 to -350 permil for $\delta^{15} \mathrm{~N}$ ), although these components appear to contribute little to the isotope variability due to their apparent scarcity (Floss et al. 2013). In summary, the Wild 2 grains display both low and high ${ }^{15} \mathrm{~N}$, indicating an unequilibrated mixture of a ${ }^{15} \mathrm{~N}$-poor material (perhaps protosolar $\mathrm{N}$ trapped in ice) component with a more refractory (high $\mathrm{C} / \mathrm{N}$ ) organic material and high $\delta^{15} \mathrm{~N}$ (McKeegan et al. 2006).

- The three oxygen isotopic compositions of silicate and oxide mineral grains from comet 81P/Wild 2 were measured using ion micro- and nanoprobe techniques. The average composition of olivine and pyroxene minerals, as well as of chondrule fragments, is consistent with average chondritic material (e.g. supplementary information in McKeegan et al. 2006; Nakamura et al. 2008; Bridges et al. 2012; Nakashima et al. 2012). In contrast, the $\mathrm{O}$-isotope ratio of the refractory phase "Inti" exhibits a $\delta^{16} \mathrm{O}$ enrichment plotting along the CCAM line with $\delta^{17} \mathrm{O}=-62 \pm 20$ permil and $\delta^{18} \mathrm{O}=-42 \pm 10$ permil (McKeegan et al. 2006, suppl. info). A detailed study of "Inti" subsequently performed by Simon et al. (2008) confirmed that Inti is indeed ${ }^{16} \mathrm{O}$-rich, with $\delta^{18} \mathrm{O} \sim \delta^{17} \mathrm{O} \sim-40$ permil. The occurrence of silicates plotting close to the Terrestrial Fractionation (TF) line together with the ${ }^{16} \mathrm{O}$-rich material (Ca-Al-rich inclusions) is in agreement with that observed in carbonaceous chondrites (McKeegan et al. 2006, suppl. info). These observations confirm that Wild 2 material contains oxides that were synthesized in the most inner regions of the solar system. Several presolar grains were identified in Stardust samples (at least 6). However, a large fraction of these tiny phases may have been destroyed during impact in the aerogel so that their initial abundance in Comet 81P/Wild 2 may have been higher than inferred from direct counting (Floss et al. 2013).

- Another interesting observation on Wild 2 material is the occurrence of CAIs as mentioned above. In the refractory minerals that were analyzed for $\mathrm{Mg}$ isotopes, no trace of the extinct ${ }^{26} \mathrm{Al}$ radioactivity $\left(T_{1 / 2}=0.7 \mathrm{Myr}\right.$ ) could be found (Matzel et al. 2010; Ogliore et al. 2012; Nakashima et al. 2015), in contrast to the case of most of CAIs of primitive meteorites. The latter incorporated live ${ }^{26} \mathrm{Al}$ with an initial, "canonical" ${ }^{26} \mathrm{Al} /{ }^{27} \mathrm{Al}$ of $5 \times 10^{-5}$, indicating early and fast $(T<1 \mathrm{Myr})$ formation of these high temperature condensates. The lack of ${ }^{26} \mathrm{Al}$ in Wild 2 material could indicate that these CAIs formed before the injection of ${ }^{26} \mathrm{Al}$ in the solar nebula, or that they formed later than a few $\mathrm{Myr}$ when all the ${ }^{26} \mathrm{Al}$ was already transformed to ${ }^{26} \mathrm{Mg}$. As these CAIs are not as refractory as those usually carrying ${ }^{26} \mathrm{Al}$ excesses in meteorites, the hypothesis of a late formation is favored. Late exchange of $\mathrm{Mg}$ isotopes through metamorphism or chemical alteration cannot either be excluded.

- Up to the Stardust sample return, noble gases had not been unambiguously identified in comets. This is unfortunate because these elements are chemically inert and have the potential to trace the physical conditions of comet formation such as the nature of ice, the formation, temperature, the composition of the ambient gas etc. Cometary light noble gases (He, Ne) have been found in Stardust aerogel (Marty et al. 2008). Gases are not located in the terminal grains implanted deeply in the foam (which were presumably dried up during the entry process). They appear to reside into the walls of the cavities formed when high velocity grains exploded during aerogel entry. The ${ }^{3} \mathrm{He} /{ }^{4} \mathrm{He}$ ratio $\left(2.5 \times 10^{-4}\right)$ is intermediate between that of the solar wind (post-D burning helium) and the protosolar nebula ratio, raising the possibility that cometary matter recorded the activity of the protoSun. By contrast, the neon isotopic composition is closer to that of $\mathrm{Ne}$ trapped in chondrites than to the solar composition, supporting the hypothesis of an asteroid-comet continuum and suggesting that this Ne component was trapped in dust and not in ice. Both 
Fig. 3 Secondary electron micrograph of a chondritic porous (CP) anhydrous IDP. From Bradley (2005)

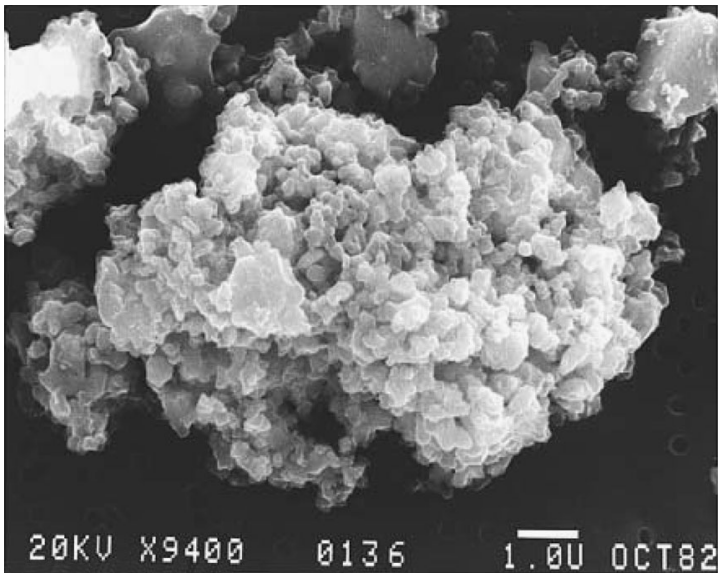

$\mathrm{He}$ and Ne from Stardust samples were released at high temperature indicating that their host is refractory (dust and/or organics) (Marty et al. 2008).

In summary, the collection of cometary grains from comet 81P/Wild 2 by the Stardust spacecraft and their analysis in the laboratory has demonstrated that a large fraction of dust trapped in this body is derived from precursors that share mineralogical and isotopic similarities with carbonaceous chondrites, that were thermally and chemically processed in the inner solar system, consistent with models advocating large scale radial mixing in the nascent solar system.

\subsection{Interplanetary Dust Particles}

Since 1981, NASA has been collecting interplanetary dust particles (IDPs) in the stratosphere, between 17-19 km altitude (Brownlee 1985). Due to their low densities, the fluffiest particles preferentially accumulate at such altitudes. Typical IDP sizes range from 1 to $\sim 50 \mu \mathrm{m}$, most particles being in the $\sim 2-15 \mu \mathrm{m}$ size range. One class of IDPs, the chondritic porous anhydrous particles (CP-IDPs, Fig. 3) are thought to originate from comets. Such chondritic porous dust particles have also been identified from Antartic snow and ice collections (Noguchi et al. 2015).

CP-IDPs mainly consist of anhydrous crystalline phases (Mg-rich olivines, pyroxenes and low-Ni Fe sulfides Bradley 2005), as well as primitive glassy components called Glass Embedded with Metals and Sulfides (GEMS) that have a debated (solar vs. presolar) origin (Bradley 2013; Keller and Messenger 2013, and references therein). Early studies on the origin of IDPs used the helium and neon release temperature in IDPs to assess the temperature reached during atmospheric entry. This entry velocity may then be related to the asteroid vs. cometary origin (Nier and Schlutter 1993). This type of analyses first suggested a cometary origin for the CP-IDPs (Brownlee et al. 1995). They are usually rich in carbonaceous matter (from $\sim 5$ to $\sim 45 \mathrm{wt} \%$, (Keller et al. 1994), and their mineralogy is compatible with that of comets 1P/Halley and C/1995 O1 (Hale-Bopp) (e.g., Hanner and Zolensky 2010; Brunetto et al. 2011, and references therein). Some larger CP-IDPs are fragmented into several patches during impact in the collector, leading to the appellation of "cluster IDPs". It has been proposed that a large proportion (if not all) of CP- or cluster IDPs are of cometary origin (e.g., Bradley and Brownlee 1986; Ishii et al. 2008, and references therein). In addition, IDPs collected in April 2003 during a period predicted to show an increase in dust flux 
from comet 26P/Grigg-Skjellerup may originate from this Jupiter-family comet (Busemann et al. 2009).

The $\mathrm{D} / \mathrm{H}$ ratios in $\mathrm{CP}$ - and cluster IDPs exhibit elevated values associated with the organic matter, typically ranging from $\mathrm{D} / \mathrm{H} \sim 10^{-4}$ to $\sim 8 \times 10^{-3}$, i.e. up to $\sim 50$ times the terrestrial value in the case of one cluster IDP (Messenger 2000 and references therein). The $\mathrm{D} / \mathrm{H}$ values of two IDPs possibly originating from the 26P/Grigg-Skjellerup collection (GSC-IDPs) also show high $\mathrm{D} / \mathrm{H}$ values with ratios ranging from $5.4 \times 10^{-4}$ to $1.5 \times 10^{-3}$.

In cluster IDPs, the nitrogen isotopes show substantial variations, with an average ${ }^{14} \mathrm{~N} /{ }^{15} \mathrm{~N}$ ratio around 236. The IDP organic matter exhibits ${ }^{15} \mathrm{~N}$-rich and ${ }^{15} \mathrm{~N}$-poor areas with $\delta^{15} \mathrm{~N}$ up to 1300 permil and $\delta^{15} \mathrm{~N}$ as low as $-93 \pm 4$ permil (Messenger 2000; Floss et al. 2006). The two GSC-IDPs have bulk ${ }^{14} \mathrm{~N} /{ }^{15} \mathrm{~N}$ values varying from $238 \pm 4$ $\left(\delta^{15} \mathrm{~N}=145 \pm 15\right.$ permil $)$ to $183 \pm 6\left(\delta^{15} \mathrm{~N}=485 \pm 35\right.$ permil $)$, with ${ }^{15} \mathrm{~N}$-rich hotspots showing ${ }^{14} \mathrm{~N} /{ }^{15} \mathrm{~N}$ values as low as $118 \pm 18\left(\delta^{15} \mathrm{~N}=1310 \pm 150\right.$ permil) (Busemann et al. 2009).

The bulk carbon isotopes in normal and cluster IDPs are within the terrestrial range. In the GSC-IDPs, there are sub-regions showing carbon isotopic anomalies $\left({ }^{12} \mathrm{C}\right.$-rich, $\delta^{13} \mathrm{C}=-280$ permil), suggesting the presence of primitive organic matter, or presolar grains (Busemann et al. 2009).

The bulk oxygen isotopic compositions of CP-IDPs are usually within the range of values observed for carbonaceous chondrites, although heavy oxygen isotopic compositions, with $\delta^{17} \mathrm{O}, \delta^{18} \mathrm{O}$ up to +80 to +200 permil, have been identified in one IDP (e.g., Starkey et al. 2014, and references therein). In the CP- and GSC-IDPs there are numerous localized isotopic anomalies suggesting an abundant content in presolar silicates, some of them possibly being GEMS (Messenger et al. 2003, 2005; Busemann et al. 2009; Keller and Messenger 2013, and references therein). The $\mathrm{O}$ isotopes are distinct in various solar system materials, and therefore provide a unique tool to trace genetic relationship between solar system reservoirs. The $\mathrm{O}$ isotopic composition of carbonaceous chondrites is related to that of chondritic porous IDPs, Stardust grains and UCAMMs (Sect. 3.3), and suggests a genetic continuum between carbonaceous chondrites and comets (Aléon 2010; Nakashima et al. 2012; Davidson et al. 2012; Starkey and Franchi 2013, and references therein).

\subsection{Ultracarbonaceous Antarctic Micrometeorites}

Micrometeorites dominated by organic matter were identified in the CONCORDIA collection (Duprat et al. 2010; Dobrică et al. 2011, 2012) and in a collection performed at Dome Fuji (Nakamura et al. 2005) (UCAMMs, for Ultracarbonaceous Antarctic Micrometeorites, Fig. 4). These particles contain more than $50 \%$ of organic matter in volume, i.e. a carbon content up to ten times that of the most $\mathrm{C}$-rich carbonaceous chondrites (e.g., Alexander et al. 2012). Such concentrations of carbonaceous matter are comparable with that of the most C-rich IDPs (Thomas et al. 1993; Keller et al. 2004), and compatible with CHON grains detected in comet Halley by the Giotto and VEGA space missions in 1986 (Kissel and Krueger 1987; Lawler and Brownlee 1992).

The hydrogen isotopic composition of UCAMMs exhibit extreme D enrichments over large areas $\left(>100 \mu \mathrm{m}^{2}\right)$, with $\mathrm{D} / \mathrm{H}$ ratios up to 10-30 times the VSMOW value (Duprat et al. 2010; Dartois et al. 2013; Slodzian et al. 2013; Bardin et al. 2014). This isotopic composition is a signature of a primitive organic matter from cold and dense regions of the protosolar cloud or protoplanetary disk. Remarkably, the extreme D excesses observed in UCAMMs are not limited to hotspots of 1-2 $\mu \mathrm{m}$ in size like usually observed in IDPs or meteoritic insoluble organic matter (e.g., Remusat et al. 2010, and references therein). The 
Fig. 4 Backscattered electron micrograph of a fragment of CONCORDIA

Ultracarbonaceous Antarctic Micrometeorite (UCAMM). All dark grey patches are constituted of organic matter. Light grey flakes are silicates, and bright spots are Fe-Ni sulfides. From Duprat et al. (2010)

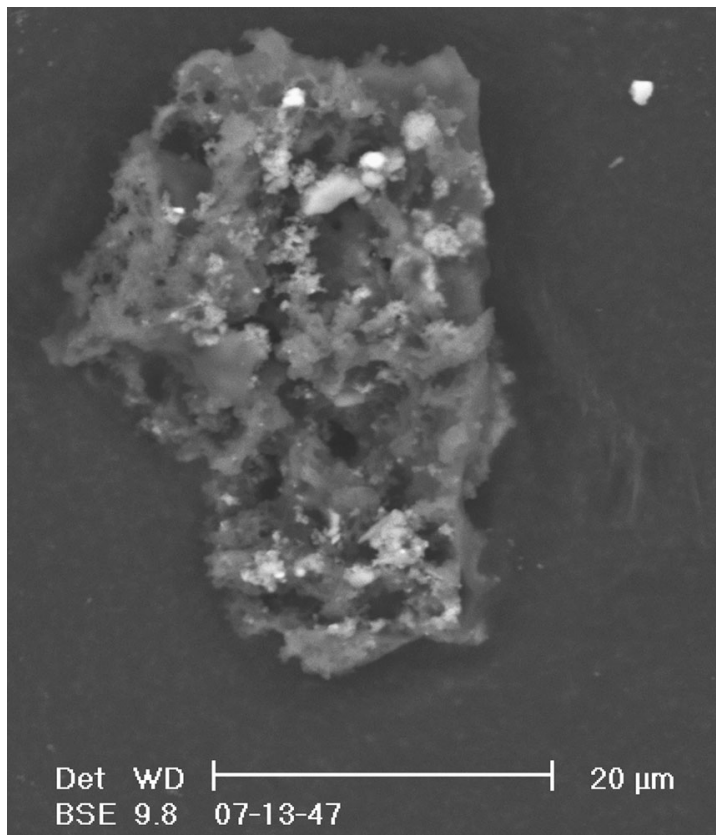

association in UCAMMs of primitive organic matter with mineral phases (including crystalline minerals) that show evidence of nebular processing (Dobrică et al. 2012), suggest that deuteration of the organic matter may have taken place in the outer regions of the protoplanetary disk rather than in the presolar molecular cloud core (Duprat et al. 2010). The organic matter itself is rich in $\mathrm{N}$ with concentrations of $\mathrm{N} / \mathrm{C}$ ratios up to 0.15 . The formation of such an $\mathrm{N}$-rich organic matter can result from long term irradiation by non-attenuated galactic cosmic rays of $\mathrm{N}_{2}-\mathrm{CH}_{4}$ rich ices present at the surface of icy bodies in the external regions of the solar system (Dartois et al. 2013).

The nitrogen isotopic composition of UCAMMs is under investigation. It reveals a heterogeneous distribution of the ${ }^{15} \mathrm{~N} /{ }^{14} \mathrm{~N}$ ratios showing both ${ }^{15} \mathrm{~N}$-rich and ${ }^{15} \mathrm{~N}$-poor regions (Duprat et al. 2014).

The oxygen isotopic composition of UCAMMs is also currently under investigation. The bulk oxygen isotopic composition of two UCAMMs plots slightly above the terrestrial fractionation line with $\delta^{18} \mathrm{O} \sim-5$ permil and $\delta^{17} \mathrm{O} \sim 10$ permil (Kakazu et al. 2014).

\subsection{Other Potential Cometary Samples on Earth}

Some of the carbonaceous chondrites, especially those of the CI type (e.g., Orgueil), as well as $\mathrm{CM}$ or CR chondrites, may represent fragments of nuclei from extinct comets (Gounelle et al. 2006; Weisberg and Connolly 2008; Haack et al. 2011). Arguments for such an origin are: (i) ellipsoidal trajectories and high entry $(18 \mathrm{~km} / \mathrm{s})$ velocities inferred from groundbased investigations, that point to a JFC origin; (ii) abundant organics (up to $5 \% \mathrm{C}$ ) and hydrated minerals (equiv. 10-20\% water), leading to an estimated water/rock ratio of about 1 , comparable to those of comets (e.g., comet 9P/Tempel 1); (iii) the similarity of oxygen isotope trends of Stardust oxides with those of carbonaceous chondrites (Sect. 3.1); (iv) elevated $\mathrm{D} / \mathrm{H}$ or ${ }^{15} \mathrm{~N} /{ }^{14} \mathrm{~N}$ ratios; v) abundance of glassy phases. Their bulk $\mathrm{D} / \mathrm{H}$ or $\mathrm{N}$ isotopic compositions are however not as elevated as those observed in comet water and $\mathrm{CN}$, 
$\mathrm{HCN}$ and $\mathrm{NH}_{3}$,respectively. If these meteorites represent cometary nuclei, this difference may be due to loss of ice-bearing $\mathrm{D}$ and ${ }^{15} \mathrm{~N}$ for CCs. Elevated $\mathrm{D} / \mathrm{H}$ ratios in hydrated phases in Semarkona (unequilibrated LL3 chondrite) were however recently measured (up to $1.8 \times 10^{-3}$ ). These phases could result for the local alteration of silicates using D-rich water (ice grain?) that could be the source of part of the water emitted by Oort cloud comets (Piani et al. 2015).

Recently, Kramers et al. (2013) claimed that a peculiar cm-sized stone found in Egypt and nicknamed Hypatia could be a comet fragment that would have exploded in the atmosphere over Northern Africa $26 \mathrm{Myr}$ ago, resulting in a glass strewnfield in the Lybian desert. Altogether, the absence of an impact crater large enough to account for the extent of the Lybian tektite field, physical considerations raised long ago (Urey 1957), and the peculiar composition of Hypatia (Kramers et al. 2013) are in agreement with such an origin. The Hypatia stone has a ${ }^{40} \mathrm{Ar} /{ }^{36} \mathrm{Ar}$ ratio lower than that of air, demonstrating an extraterrestrial origin. It is rich in carbon in the cubic form and hosts abundant nano- to microdiamonds. Hypatia's $\mathrm{C}$ isotope composition also clearly indicate an extraterrestrial origin and noble gas isotope signatures suggest the occurrence of unequilibrated material containing dust from AGB stars winds. Further elemental and isotopic measurements are underway to explore this exciting possibility.

\section{Discussion}

One viewpoint for the origin of cometary materials is that they are pristine remnants of the interstellar material that collapsed to form the solar nebula Greenberg (1982). Alternatively, cometary molecules may have formed in the cold outer regions of the solar nebula regions. The analogy between cometary and interstellar ice-composition indeed suggests that those materials formed by similar processes, i.e., ion-molecule and grain-surface reactions at low temperatures (Bockelée-Morvan et al. 2000). However, the presence of crystalline silicates and other high temperature condensates in comets indicates that comets incorporated also materials formed in the hot innermost regions of the disk (Brownlee et al. 2006; BockeléeMorvan et al. 2002; Wooden 2008), or which underwent processing through, e.g., nebular shocks (Harker and Desch 2002), or in the surface layers during protosolar luminosity outbursts (Ábrahám et al. 2009). In the latter two cases, where a purely nebular origin may be indicated, mixing of material radially outwards or vertically downwards to the midplane, would also lead to cometary ices having a composition derived from a chemistry radically different from that of the interstellar medium.

Isotopic ratios in comets can provide constraints to the different scenarios. The ISMcomet connection can be tested by comparing isotopic ratios in both kinds of material. Tables 4 and 5 provide respectively hydrogen and nitrogen isotopic ratios measured in molecular clouds, dark cores and protostars.

\subsection{Interstellar Isotopic Fractionation}

Cosmic rays drive an ion-molecule chemistry in dense interstellar clouds. At the cold temperatures of these environments $(\sim 10 \mathrm{~K})$ the zero-point energy difference between isotopically-substituted molecules can become important in exothermic ion-molecule reactions. For example, although D isotope-exchange reactions of the form

$$
\mathrm{XH}^{+}+\mathrm{HD} \rightleftharpoons \mathrm{XD}^{+}+\mathrm{H}_{2}+\Delta \mathrm{E}
$$


Table 3 Ion-molecule isotopic exchange reactions

\begin{tabular}{|c|c|c|c|}
\hline No. & Reaction & $\Delta E / k(\mathrm{~K})$ & Reference \\
\hline $\mathrm{R} 1$ & $\mathrm{H}_{3}^{+}+\mathrm{HD} \rightleftharpoons \mathrm{H}_{2} \mathrm{D}^{+}+\mathrm{H}_{2}$ & 143.0 & Giles et al. 1992 \\
\hline R2 & $\mathrm{H}_{2} \mathrm{D}^{+}+\mathrm{HD} \rightleftharpoons \mathrm{HD}_{2}^{+}+\mathrm{H}_{2}$ & 187.0 & Giles et al. 1992 \\
\hline $\mathrm{R} 3$ & $\mathrm{HD}_{2}^{+}+\mathrm{HD} \rightleftharpoons \mathrm{D}_{3}^{+}+\mathrm{H}_{2}$ & 234.0 & Giles et al. 1992 \\
\hline R4 & $\mathrm{CH}_{3}^{+}+\mathrm{HD} \rightleftharpoons \mathrm{CH}_{2} \mathrm{D}^{+}+\mathrm{H}_{2}$ & 370.0 & Millar et al. 1989 \\
\hline $\mathrm{R} 5$ & $\mathrm{C}_{2} \mathrm{H}_{2}^{+}+\mathrm{HD} \rightleftharpoons \mathrm{C}_{2} \mathrm{HD}^{+}+\mathrm{H}_{2}$ & 550.0 & Millar et al. 1989 \\
\hline R6 & ${ }^{13} \mathrm{C}^{+}+{ }^{12} \mathrm{CO} \rightleftharpoons{ }^{12} \mathrm{C}^{+}+{ }^{13} \mathrm{CO}$ & 35.0 & Watson et al. 1976 \\
\hline $\mathrm{R} 7 \mathrm{a}$ & ${ }^{14} \mathrm{~N}_{2} \mathrm{H}^{+}+{ }^{14} \mathrm{~N}^{15} \mathrm{~N} \rightleftharpoons{ }^{14} \mathrm{~N}^{15} \mathrm{NH}^{+}+{ }^{14} \mathrm{~N}_{2}$ & 10.7 & Adams and Smith 1981 \\
\hline $\mathrm{R} 7 \mathrm{~b}$ & ${ }^{14} \mathrm{~N}_{2} \mathrm{H}^{+}+{ }^{14} \mathrm{~N}^{15} \mathrm{~N} \rightleftharpoons{ }^{15} \mathrm{~N}^{14} \mathrm{NH}^{+}+{ }^{14} \mathrm{~N}_{2}$ & 2.3 & Adams and Smith 1981 \\
\hline R8 & ${ }^{15} \mathrm{~N}^{+}+{ }^{14} \mathrm{~N}_{2} \rightleftharpoons{ }^{14} \mathrm{~N}^{+}+{ }^{14} \mathrm{~N}^{15} \mathrm{~N}$ & 28.3 & Terzieva and Herbst 2000 \\
\hline R9 & ${ }^{15} \mathrm{~N}^{+}+{ }^{14} \mathrm{NO} \rightleftharpoons{ }^{14} \mathrm{~N}^{+}+{ }^{15} \mathrm{NO}$ & 24.3 & Terzieva and Herbst 2000 \\
\hline R10a & ${ }^{15} \mathrm{~N}+{ }^{14} \mathrm{~N}_{2} \mathrm{H}^{+} \rightleftharpoons{ }^{14} \mathrm{~N}+{ }^{14} \mathrm{~N}^{15} \mathrm{NH}^{+}$ & 36.1 & Terzieva and Herbst 2000 \\
\hline $\mathrm{R} 10 \mathrm{~b}$ & ${ }^{15} \mathrm{~N}+{ }^{14} \mathrm{~N}_{2} \mathrm{H}^{+} \rightleftharpoons{ }^{14} \mathrm{~N}+{ }^{15} \mathrm{~N}^{14} \mathrm{NH}^{+}$ & 27.7 & Terzieva and Herbst 2000 \\
\hline R11 & ${ }^{15} \mathrm{~N}+\mathrm{C}^{14} \mathrm{NC}^{+} \rightleftharpoons{ }^{14} \mathrm{~N}+\mathrm{C}^{15} \mathrm{NC}^{+}$ & 36.4 & Terzieva and Herbst 2000 \\
\hline $\mathrm{R} 12$ & ${ }^{15} \mathrm{~N}+\mathrm{HC}^{14} \mathrm{NH}^{+} \rightleftharpoons{ }^{14} \mathrm{~N}+\mathrm{HC}^{15} \mathrm{NH}^{+}$ & 35.9 & Terzieva and Herbst 2000 \\
\hline
\end{tabular}

are exothermic in the forward direction (to the right) the higher abundance of $\mathrm{H}_{2}$ relative to $\mathrm{HD}\left(\mathrm{H}_{2} / \mathrm{HD} \sim 2 \times 10^{-5}\right)$ means that the reverse reaction will dominate except at very low temperatures. Table 3 lists the major ion-molecule reactions leading to isotopic fractionation in low-temperature interstellar clouds. Although reaction (R1) has long been known to initiate D fractionation in molecular clouds (e.g., Millar et al. 1989), the enhanced depletion of $\mathrm{CO}$ onto dust and the low electron fractions found in high-density molecular cores both conspire to permit reactions (R2) and (R3) to play important roles (Roberts et al. 2003). The spin-state of the colliding $\mathrm{H}_{2}$ molecules, whether para or the higher-energy ortho state, plays an important role in interstellar fractionation. The higher internal energy of ortho- $\mathrm{H}_{2}$ can essentially quench ion-molecule deuteration when the ortho/para ratio (OPR) is high (Pagani et al. 2011). In such CO depletion cores, where protostars are about to form, gasphase deuteration is enhanced and, as $\mathrm{D}_{3}^{+}$becomes the major ion, this leads to very high atomic $\mathrm{D} / \mathrm{H}$ ratios. Atom addition reactions on dust, primarily starting from condensed $\mathrm{CO}$, can lead to many organic compounds, such as formaldehyde, methanol, formic acid, acetaldehyde, isocyanic acid and formamide, molecules which are also identified in comets (e.g., Charnley and Rodgers 2008; Herbst and van Dishoeck 2009). High atomic D/H ratios in the condensing gas consequently leads to very high $\mathrm{D} / \mathrm{H}$ ratios and the formation of many multiply-deuterated isotopologues for surface-formed molecules (Charnley et al. 1997); these latter species include $\mathrm{D}_{2} \mathrm{O}, \mathrm{D}_{2} \mathrm{CO}, \mathrm{CHD}_{2} \mathrm{OH}, \mathrm{CD}_{3} \mathrm{OH}, \mathrm{NHD}_{2}, \mathrm{ND}_{3}$ and $\mathrm{D}_{2} \mathrm{~S}$ (Parise et al. 2006; Ceccarelli et al. 2014). These characteristics are observed in the interstellar medium and Table 4 summarizes the range of $\mathrm{D} / \mathrm{H}$ ratios found in cold dark clouds and in cores forming both low-mass and massive protostars. In the latter regions the highest $\mathrm{D} / \mathrm{H}$ ratios are due to highly-fractionated ices being evaporated from warm dust grains (e.g., Charnley et al. 1997).

Reaction (R6) is the primary ion-molecule means of fractionating carbon in interstellar molecules. At low temperatures this has the effect that most ${ }^{13} \mathrm{C}$ nuclei become incorporated into ${ }^{13} \mathrm{CO}$, leading to a relative depletion of ${ }^{13} \mathrm{C}$ in other interstellar molecules. This can have the secondary consequence that molecules formed on grains should have ${ }^{12} \mathrm{C} /{ }^{13} \mathrm{C}$ ratios similar to that of the accreted $\mathrm{CO}$ molecules in their carbonyl or carboxyl functional 
Table 4 Interstellar deuterium fractionation ratios (\%)

\begin{tabular}{llll}
\hline Molecule & Cold molecular clouds ${ }^{1}$ & Low-mass protostars & \\
\hline $\mathrm{HDO}$ & - & $0.04-8$ & High-mass protostars $^{3}$ \\
& & $0.03-18$ & $0.03-2$ \\
$\mathrm{NH}_{2} \mathrm{D}$ & $5-13$ & $7-10$ & 0.7 \\
$\mathrm{DCN}$ & $1-7$ & $0.4-7$ & $0.05-2$ \\
$\mathrm{DNC}$ & $1-13$ & $2-6$ & $0.06-12$ \\
$\mathrm{CH}_{2} \mathrm{DOH}$ & 10 & $37-65$ & 0.06 \\
$\mathrm{CH}_{3} \mathrm{DOD}$ & $1-3$ & $1-5$ & 0.05 \\
$\mathrm{HDCO}$ & $7-10$ & $2-17$ & $0.07-14$ \\
$\mathrm{D}_{2} \mathrm{CO}$ & - & $5-44$ & 0.3 \\
$\mathrm{HDS}$ & - & $5-15$ & $<2$ \\
$\mathrm{DC}$ & & - & 1.5
\end{tabular}

${ }^{1}$ Ratios for L1544, TMC-1, L183: Howe et al. (1994), Turner (2001), Shah and Wootten (2001), Lis et al. (2008), Bizzocchi et al. (2014)

${ }^{2}$ Ratios from compilation of Taquet et al. (2014) for several protostars; exception is that DNC ratios are from Butner and Charnley (unpublished work). For HDO, values for the inner and outer regions of the protostellar envelope are given

${ }^{3}$ Ratios for various sub-components of Orion-KL (Hot Core, Compact Ridge, Extended Ridge), see for example Blake et al. (1987), Turner (1990), Minh et al. (1990), Mangum et al. (1991), Bergin et al. (2010), Esplugues et al. (2013), Neill et al. (2013). Entry for DNC is from the sample of Fontani et al. (2014)

groups, whereas other functional groups formed by addition of $\mathrm{C}$ atoms should be relatively depleted in ${ }^{13} \mathrm{C}$ (Charnley et al. 2004). Observations have confirmed this in the case of CO and methanol (Wirström et al. 2011). Isotope-selective photodissociation (Bally and Langer 1982) can also fractionate carbon in molecular clouds. In this case, the self-shielding of ${ }^{12} \mathrm{CO}$ molecules leads to regions where ${ }^{13} \mathrm{CO}$ is preferentially destroyed. However, most work has been focussed on understanding the concomitant fractionation resulting from isotopeselective photodissociation of ${ }^{12} \mathrm{C}^{18} \mathrm{O}$ and ${ }^{12} \mathrm{C}^{17} \mathrm{O}$ in the context of understanding the origin of the ${ }^{16} \mathrm{O}:{ }^{17} \mathrm{O}:{ }^{18} \mathrm{O}$ ratios measured in primitive meteoritic matter (Lee et al. 2008). Ionmolecule reactions involving oxygen isotopes produce negligible fractionation in interstellar clouds (Langer et al. 1984).

Significant isotopic enrichments in N-bearing interstellar molecules (relative to a putative ${ }^{14} \mathrm{~N} /{ }^{15} \mathrm{~N}$ elemental ratio of 440 ) can occur by the set of ion-molecule reactions listed in Table 3. Table 5 summarizes the ${ }^{14} \mathrm{~N} /{ }^{15} \mathrm{~N}$ ratios measured in molecular clouds and in the earliest phase of low-mass star formation ('Class 0').

Early chemical models of dense cores, in which nitrogen was assumed to be initially fully molecular, predicted that fractionation in amines is dependent on the level of CO depletion, as well as low temperatures. (Charnley and Rodgers 2002). Rodgers and Charnley (2008) showed that when $\mathrm{N}$ atoms are initially abundant, as one might expect since dense clouds form from diffuse gas, then reaction (R12) efficiently incorporates ${ }^{15} \mathrm{~N}$ into $\mathrm{HC}^{15} \mathrm{NH}^{+}$. Electron dissociative recombination of $\mathrm{HC}^{15} \mathrm{NH}^{+}$then produces $\mathrm{HC}^{15} \mathrm{~N}, \mathrm{H}^{15} \mathrm{NC}$ and $\mathrm{C}^{15} \mathrm{~N}$ and to ${ }^{15} \mathrm{~N}$ enrichment in nitriles early in dense cloud evolution. These chemical models predict that nitriles should be more enriched than amines (Rodgers and Charnley 2008), as observed (Table 5). Thus, interstellar ${ }^{15} \mathrm{~N}$ fractionation follows two distinct pathways, one rapid, involving $\mathrm{N}_{2}$ and $\mathrm{NH}_{3}$, and the other one much slower, involving atomic $\mathrm{N}$, and responsible for the ${ }^{15} \mathrm{~N}$ enrichment in $\mathrm{HCN}$ and other nitriles (Table 3). It is then possible that $\mathrm{N}_{2}$ and 
Table 5 Interstellar nitrogen isotope ratios

\begin{tabular}{|c|c|c|c|c|c|c|c|}
\hline Source & Type & $\mathrm{NH}_{3}$ & $\mathrm{~N}_{2} \mathrm{H}^{+}$ & $\mathrm{HCN}$ & $\mathrm{HNC}$ & $\mathrm{CN}$ & Reference \\
\hline L1544 & dark core & $>700$ & $1000 \pm 200$ & $140-360$ & $>27$ & $500 \pm 75$ & $1,2,3,4,5$ \\
\hline L1498 & dark core & - & - & $>75$ & $>90$ & $500 \pm 75$ & 4,5 \\
\hline L1521E & dark core & - & - & $151 \pm 16$ & - & - & 6 \\
\hline $\mathrm{L} 1521 \mathrm{~F}$ & dark core ${ }^{\S}$ & - & - & $>51$ & $24-31$ & - & 4,4 \\
\hline L183 & dark core & $530 \pm_{180}^{570}$ & - & $140-250$ & - & - & 1,3 \\
\hline $\mathrm{NGC}^{1333-\mathrm{DCO}^{+}}$ & dark core & $360 \pm \pm_{110}^{260}$ & - & - & - & - & 1 \\
\hline NGC 1333-4A & Class 0 protostar & $344 \pm 173$ & - & - & - & - & 7 \\
\hline Barnard 1 & Class 0 protostar & $300 \pm 40$ & $400 \pm_{65}^{100}$ & $330 \pm{ }_{50}^{60}$ & $225 \pm_{45}^{75}$ & $290 \pm \pm_{80}^{160}$ & 8 \\
\hline L1689N & Class 0 protostar & $810 \pm_{250}^{600}$ & - & - & - & - & 4 \\
\hline Cha-MMS1 & Class 0 protostar & - & - & - & 135 & - & 9 \\
\hline IRAS 16293A & Class 0 protostar & - & - & $163 \pm 20$ & $242 \pm 32$ & - & 10 \\
\hline R Cr A IRS7B & Class 0 protostar & - & - & $287 \pm 36$ & $259 \pm 34$ & - & 10 \\
\hline OMC-3 MMS6 & Class 0 protostar & - & - & $366 \pm 86$ & $460 \pm 65$ & - & 10 \\
\hline
\end{tabular}

References: (1) Gérin et al. (2009); (2) Bizzocchi et al. (2013); (3) Hily-Blant et al. (2013a); (4) Milam and Charnley (2012); (5) Hily-Blant et al. (2013b); (6) Ikeda et al. (2002); (7) Lis et al. (2010); (8) Daniel et al. (2013); (9) Tennekes et al. (2006); (10) Wampfler et al. (2014). For Barnard 1, the entry for the $\mathrm{N}_{2} \mathrm{H}^{+}$ratios is that for ${ }^{14} \mathrm{~N}^{15} \mathrm{NH}^{+}$; a lower limit of 600 is obtained for the ratio derived from ${ }^{15} \mathrm{~N}^{14} \mathrm{NH}^{+}$

${ }^{\S}$ L1521F does contain a very low luminosity object (VeLLO, Bourke et al. 2006)

$\mathrm{NH}_{3}$ result from the separation of the nitrogen into at least two distinct reservoirs, with distinct ${ }^{15} \mathrm{~N}$ enrichment, which never equilibrated. However, because of the small energy barrier for the first step of the ion-molecule reaction sequence

$$
\mathrm{N}^{+} \stackrel{\mathrm{H}_{2}}{\longrightarrow} \mathrm{NH}^{+} \stackrel{\mathrm{H}_{2}}{\longrightarrow} \mathrm{NH}_{2}^{+} \stackrel{\mathrm{H}_{2}}{\longrightarrow} \mathrm{NH}_{3}^{+} \stackrel{\mathrm{H}_{2}}{\longrightarrow} \mathrm{NH}_{4}^{+} \stackrel{e^{-}}{\longrightarrow} \mathrm{NH}_{3}, \mathrm{NH}_{2}
$$

Ammonia formation also depends on the $\mathrm{H}_{2}$ ortho/para spin ratio (OPR) - the higher energy ortho form can overcome the reaction barrier (Wirström et al. 2012). This can lead to reaction (R8) becoming important when the OPR is very small and to both enrichment and depletion of ${ }^{15} \mathrm{~N}$ in $\mathrm{NH}_{3}$ as the cloud core evolves.

The high ${ }^{14} \mathrm{~N}_{2} /{ }^{14} \mathrm{~N}^{15} \mathrm{~N}$ ratio measured in L1544 and Barnard 1 (Table 5) is a puzzle currently unresolved by existing models. The inefficiency of isotope-selective photodissociation of ${ }^{14} \mathrm{~N}_{2}$ and ${ }^{14} \mathrm{~N}^{15} \mathrm{~N}$ in molecular clouds (Heays et al. 2014) means that this process is excluded as a possible solution. The two existing measurements suggest a connection to the ammonia fractionation and measurements of these ratios in more sources is required.

The two existing measurements suggest a connection to the ammonia fractionation, and measurements of these ratios in more sources is now required. However, very recently, Roueff et al. (2015) published a study which re-assessed several of the ion-molecule fractionation pathways proposed by Terzieva and Herbst (2000), quantified some of the neutralneutral reactions suggested by Rodgers and Charnley (2008), and considered new fractionation reactions for ${ }^{13} \mathrm{C}$. Quantum-chemical calculations presented by Roueff et al. show that, in conflict with Terzieva and Herbst (2000), reactions (R9), (R10a), (R10b) and (R12) in Table 3 each possess activation energy barriers that will lead to negligible rates at around $10 \mathrm{~K}$. Model calculations incorporating these new data indicate that, as expected, the calculated 
${ }^{14} \mathrm{~N} /{ }^{15} \mathrm{~N}$ ratios in $\mathrm{HCN}$ and $\mathrm{HNC}$ are much less enriched in ${ }^{15} \mathrm{~N}$ than predicted in earlier models (e.g., Rodgers and Charnley 2008) and is observed (see Table 3). The calculations of Roueff et al. also predict that the $\left({ }^{14} \mathrm{~N} /{ }^{15} \mathrm{~N}\right.$ ratio in $\mathrm{N}_{2} \mathrm{H}^{+}$should be close to elemental $(\approx 400)$, in contrast to the depleted ratios observed in L1544 $(\sim 1000$, Bizzocchi et al. 2013 ) and the enrichments predicted by previous theoretical models (e.g., Wirström et al.

2012). Thus, when compared to much of the published literature on interstellar ${ }^{15} \mathrm{~N}$ fractionation, the work of Roueff et al. demonstrates that our current theoretical understanding of the underlying gaseous fractionation processes is far from complete.

\subsection{Deuteration in the Solar Nebula}

Cometary $\mathrm{D} / \mathrm{H}$ values are lower than in most interstellar sources (Tables 1,4$)$. This low deuterium fractionation in comets can be interpreted by ion-molecule chemistry in gas phase at 25-35 K (Meier et al. 1998a, 1998b). Ion-molecule reactions in the outer solar nebula could also act to lower the interstellar fractionation (Aikawa and Herbst 1999). Alternatively, the low D-enrichment in $\mathrm{H}_{2} \mathrm{O}$ might result from the mixing of D-rich water vapor originating from the pre-solar cloud or outer cold disk, and material reprocessed in the inner hot solar nebula (Hersant et al. 2001; Mousis et al. 2000; Kavelaars et al. 2011). Indeed, at high temperatures $(>500 \mathrm{~K})$, water molecules quickly exchange their deuterium with the main hydrogen reservoir $\mathrm{H}_{2}$, so that the deuterium enrichment in water can not exceed the protosolar value of $0.21 \pm 0.04 \times 10^{-4}$ by more than a factor of 3 (Geiss and Gloeckler 1998) in high- $T$ conditions. Transport mechanisms invoked so far include turbulent diffusion, which is also responsible for angular momentum transport in the solar nebula. Models are able to explain both the low, i.e. terrestrial, bulk deuterium enrichment measured in meteorites and the $\mathrm{D} / \mathrm{H}$ ratio of $\sim 3 \times 10^{-4}$ measured in the water of Oort cloud comets, and Enceladus's plume (Hersant et al. 2001; Kavelaars et al. 2011; Waite et al. 2009). The higher deuterium enrichment in HCN measured in the Oort cloud comet Hale-Bopp (compared to the value in $\mathrm{H}_{2} \mathrm{O}$ ) might be explained by a lower efficiency of deuterium exchange between $\mathrm{HCN}$ and $\mathrm{H}_{2}$ in the solar nebula (Mousis et al. 2000).

These models also predict that comets formed at higher distances from the Sun should exhibit higher $\mathrm{D} / \mathrm{H}$ ratios as they incorporated less processed material from the inner solar nebula. It was generally agreed that Oort-cloud comets formed closer to the Sun than Jupiterfamily comets (Dones et al. 2004, and references therein). However, in the framework of the Nice model, the Oort-cloud and the Scattered Disk, which is the source of the Jupiterfamily comets, formed together as a result of late planetary migration which dispersed the trans-neptunian disk (Brasser and Morbidelli 2013). Therefore, in this picture, Jupiterfamily comets are expected to exhibit similar or larger $\mathrm{D} / \mathrm{H}$ than the Oort-cloud comets. The high deuterium enrichment measured in comet 67P/Churyumov-Gerasimenko is in line with these models (Altwegg et al. 2014), whereas the ocean-like D/H value found in the water of the Jupiter-family comets 103P/Hartley 2 and 45P/Honda-Mrkos-Pajdušáková is not. More recent calculations of the $\mathrm{D} / \mathrm{H}$ distribution in the solar nebula showed that it is possible to obtain a non-monotonic gradient of the $\mathrm{D} / \mathrm{H}$ ratio if fresh material from the infalling outer envelope fed the solar nebula continuously (Yang et al. 2013). Jacquet and Robert (2013) suggest that deuterium-poor ice grains condensed at the snow line were transported outwards in the comet-formation region, via turbulent diffusion. This scenario could also explain the distribution of $\mathrm{D} / \mathrm{H}$ in $\mathrm{CCs}$.

Another possible solution is that the Jupiter-family comets 103P/Hartley 2 and 45P/ Honda-Mrkos-Pajdušáková formed closer to the Sun than other comets. According to the Grand Tack scenario, when the giant planets were still embedded in the nebular gas disk, 
there was a general radial mixing of the distribution of comets and asteroids (Walsh et al. 2011) so that the Kuiper Belt was populated by objects formed in a large range of heliocentric distance. Both the similarity of the $\mathrm{D} / \mathrm{H}$ ratio in comets 103P/Hartley 2 and 45P/HondaMrkos-Pajdušáková with that found in carbonaceous chondrites, and the isotopic diversity observed in the Oort-cloud and Jupiter-family populations of comets are in agreement with such a scenario.

It was generally admitted that the extreme D-enrichments observed in primitive meteorites and IDPs are reflecting those acquired in the presolar cloud. The discovery of large D enrichments over large areas $\left(>100 \mu \mathrm{m}^{2}\right)$ of carbonaceous matter in UCAMMs would then require a large degree of preservation of such D-rich matter. Alternatively, cold chemistry in the outer regions of the protoplanetary disk could be responsible for such enrichments. The negative correlation between the $\mathrm{D} / \mathrm{H}$ ratios of the $\mathrm{CH}$ bonds and their binding energy in the Insoluble Organic Matter of Orgueil carbonaceous meteorite also suggests that deuterium enrichments could have been acquired within the protoplanetary disk itself (Remusat et al. 2006). Whether this mechanism affected the D-fractionation observed in cometary HCN and $\mathrm{H}_{2} \mathrm{O}$ has still to be investigated. Recent work by Cleeves et al. (2014) has demonstrated that, if cosmic-rays cannot penetrate the protosolar disk, then nebular chemistry alone cannot generate the $\mathrm{D} / \mathrm{H}$ ratios measured in primitive materials such as comets and meteorites. In this case, all the D fractionation in the nebula must be directly inherited from the interstellar medium (Willacy et al. 2015).

\subsection{Nitrogen Isotopes}

In the solar system the ${ }^{14} \mathrm{~N} /{ }^{15} \mathrm{~N}$ ratio presents variations that remain difficult to interpret (Fig. 2). The analysis of Genesis solar wind samples (Marty et al. 2011), considered as representative of the protosolar nebula, provided a ${ }^{14} \mathrm{~N} /{ }^{15} \mathrm{~N}$ ratio of $441 \pm 5$. This value is in agreement with the in situ measurements made in the ammonia of Jupiter's atmosphere (Fouchet et al. 2004) which probably comes from primordial $\mathrm{N}_{2}$ (Owen et al. 2001). These values differs from the terrestrial ratio measured in the atmospheric $\mathrm{N}_{2}$ (272). The Earth's ratio is enriched in ${ }^{15} \mathrm{~N}$ compared to the protosolar nebula and is similar to the bulk of ratios derived from the analysis of comet 81P/wild 2 grains (McKeegan et al. 2006). Nitrogen isotopic ratios have also been measured in Titan's atmosphere. This atmosphere is dominated by $\mathrm{N}_{2}$ molecules and two in situ measurements, based on Cassini GCMS and INMS data (Niemann et al. 2010; Mandt et al. 2009) have been published: $167.7 \pm 0.6$ and 143. Because of the low abundance of primordial Ar observed by Cassini-Huygens, it is generally assumed that $\mathrm{N}_{2}$ is of secondary origin in this atmosphere and was delivered in a less-volatile form, probably $\mathrm{NH}_{3}$.

In comets, a similar ${ }^{15} \mathrm{~N}$ enrichment is observed for both $\mathrm{CN} / \mathrm{HCN}$ and ammonia (Fig. 2). This is in contrast with interstellar sources where molecules carrying the nitrile $(-\mathrm{CN})$ functional group are more enriched in ${ }^{15} \mathrm{~N}$ than the molecules carrying the amine $(-\mathrm{NH})$ functional group (Table 5). As discussed in Sect. 4.1, the different studies of interstellar chemistry are able to explain the ${ }^{15} \mathrm{~N}$ enrichment measured for cometary HCN but this is less clear for ammonia (Sect. 4.1).

Ion-molecule chemistry in dense interstellar and/or protostellar material could induce ${ }^{15} \mathrm{~N}$ enrichment in the ammonia ice produced in such environments (Charnley and Rodgers 2002). Alternatively, the ${ }^{15} \mathrm{~N}$ enrichment observed in cometary ices could result from isotopic fractionation processes that occurred in the late protosolar nebula (Aléon 2010).

A property of primitive solar system material, is that there is no strict correlation between deuterium and ${ }^{15} \mathrm{~N}$ enrichments (Aléon 2010; Marty 2012, and references therein). Interest- 
ingly, Wirström et al. (2012) show that while the nitriles, HCN and HNC, have the greatest

${ }^{15} \mathrm{~N}$ enrichment, this enrichment is not expected to correlate with extreme D enrichments.

Finally, models considering self-shielding of $\mathrm{N}_{2}$ photodissociation can explain enrichment in ${ }^{15} \mathrm{~N}$ for $\mathrm{HCN}$, but for ammonia the enrichment in ${ }^{15} \mathrm{~N}$ depends on the place in the nebula (Heays et al. 2014).

\section{Prospects for the Future}

\subsection{Measurements from Rosetta}

\subsubsection{ROSINA}

Mass spectrometry is a powerful tool to measure the isotopic ratios of the light volatiles in simple species of the coma. Mass spectrometers with high resolution (to resolve molecules on integer mass) and high dynamic range (to detect minor species) are required. On board the Rosetta orbiter is the Rosetta Orbiter Spectrometer for Ion and Neutral Analysis experiment (ROSINA). Its aim is to characterize in situ the volatiles in the coma of 67P/ChuryumovGerasimenko (Balsiger et al. 2007). ROSINA consists of two complementary mass spectrometers, the Double Focusing Mass Spectrometer (DFMS) and the Reflectron Time of Flight mass spectrometer (RTOF), and a pressure sensor (COPS). DFMS has a mass per charge range of 12-150 amu/e and a mass resolution of 9000 at $50 \%$ peak height at mass 28 . It is optimized for very high mass resolution and large dynamic range and can resolve, e.g., $\mathrm{CO}$ and $\mathrm{N}_{2}$ on mass/charge $28 \mathrm{amu} / \mathrm{e}$, or ${ }^{12} \mathrm{CH}$ and ${ }^{13} \mathrm{C}$ on mass/charge $13 \mathrm{amu} / \mathrm{e}$ (Balsiger et al. 2007).

Since the first encounter at a comet by VEGA 1 on March 6, 1986, there have been several missions to comets, like Deep Space (19P/Borrelly), Stardust (81P/Wild 2), and Deep Impact (9P/Tempel 1). However, since Giotto none of them carried a mass spectrometer for in situ investigations of the gas coma. ROSINA will provide information about $\mathrm{H}_{2} \mathrm{O}$ and other molecules in the coma (e.g., abundance of $\mathrm{CO}$ and $\mathrm{N}_{2}$, Rubin et al. 2015, local abundances in the coma, extended sources, e.g., $\mathrm{CN}$, etc.) and measure the isotopic composition of several species. In the following is a discussion of the capability of ROSINA to measure isotopic ratios.

For the light volatiles $\mathrm{H}, \mathrm{C}, \mathrm{N}, \mathrm{O}$, and $\mathrm{S}$, DFMS is expected to measure at least the isotopic ratio in one molecule: for $\mathrm{D} / \mathrm{H}$ in $\mathrm{H}_{2} \mathrm{O}$ as it has been shown by Hässig et al. (2013), for ${ }^{13} \mathrm{C} /{ }^{12} \mathrm{C}$ in $\mathrm{CH}_{4}, \mathrm{CO}_{2}, \mathrm{H}_{2} \mathrm{CO}$, for ${ }^{15} \mathrm{~N} /{ }^{14} \mathrm{~N}$ directly in $\mathrm{N}$, for ${ }^{17} \mathrm{O} /{ }^{16} \mathrm{O}$ in $\mathrm{H}_{2} \mathrm{O}$, for ${ }^{18} \mathrm{O} /{ }^{16} \mathrm{O}$ in $\mathrm{H}_{2} \mathrm{O}$, and for the sulfur isotopes directly in $\mathrm{S}$ and $\mathrm{H}_{2} \mathrm{~S}$. There are three factors which influence whether an isotopologue can be detected or not:

- Mass resolution of DFMS, e.g., it is not possible to resolve the isotopologues of HCN.

- Abundance of main species and dynamic range: e.g., in order to determine the ratio of oxygen the peaks on mass 16 and 17 are needed since the signal for ${ }^{17} \mathrm{O}$ has to be separated from ${ }^{16} \mathrm{OH}$, which might be much more abundant and thus hide the signal of ${ }^{17} \mathrm{O}$. First results were derived already during the comet approach phase (see Sect. 2.1.1, Altwegg et al. 2014), and further results are expected in summer 2015 when 67P/ChuryumovGerasimentko is at its perihelion.

- Some species are already present in the spacecraft background, e.g., $\mathrm{CH}_{4}$ and $\mathrm{HCN}$ (for entire inventory see SchläPpi et al. 2010) and have to be accounted for.

An overview about the detection capabilities for isotopic ratios at comet 67P/ChuryumovGerasimenko is given in Table 6. 
Table 6 An overview on the detection capabilities of ROSINA for the light volatiles. The table is based on the current knowledge about abundances and isotopic ratios on comets (Bockelée-Morvan 2011; Jehin et al. 2009; Rousselot et al. 2014)

\begin{tabular}{|c|c|c|c|c|c|}
\hline & Target species & Mass (amu) & Closest neighbour & Mass (amu) & Feasibility \\
\hline \multirow[t]{5}{*}{$\mathrm{D} / \mathrm{H}$} & HDO & 19.0163 & $\mathrm{H}_{2}^{17} \mathrm{O}$ & 19.0142 & $\checkmark$ \\
\hline & $\mathrm{NH}_{2} \mathrm{D}$ & 18.0323 & ${ }^{15} \mathrm{NH}_{3}$ & 18.0230 & $(\checkmark)$ \\
\hline & $\mathrm{CH}_{3} \mathrm{D}$ & 17.0370 & ${ }^{13} \mathrm{CH}_{4}$ & 17.0341 & $(\checkmark)$ \\
\hline & $\mathrm{DCN}$ & 28.0166 & $\mathrm{CH}_{2} \mathrm{~N}$ & 28.0182 & - \\
\hline & & & $\mathrm{H}^{13} \mathrm{CN}$ & 28.0137 & \\
\hline \multirow[t]{9}{*}{${ }^{13} \mathrm{C} /{ }^{12} \mathrm{C}$} & ${ }^{13} \mathrm{CH}_{3} \mathrm{D}$ & 18.0404 & $\mathrm{NDH}_{2}$ & 18.0323 & $(\checkmark)$ \\
\hline & ${ }^{13} \mathrm{C}$ & 13.0028 & $\mathrm{CH}$ & 13.0073 & $\checkmark$ \\
\hline & ${ }^{13} \mathrm{CH}_{4}$ & 17.0341 & $\mathrm{CH}_{3} \mathrm{D}$ & 17.0370 & $\checkmark$ \\
\hline & $\mathrm{H}^{13} \mathrm{CN}$ & 28.0137 & $\mathrm{DCN}$ & 28.0166 & - \\
\hline & & & $\mathrm{CH}_{2} \mathrm{~N}$ & 28.0182 & \\
\hline & ${ }^{13} \mathrm{CN}$ & 27.0059 & $\mathrm{HCN}$ & 27.0104 & $(\checkmark)$ \\
\hline & ${ }^{13} \mathrm{CO}_{2}$ & 44.9926 & $\mathrm{CHO}_{2}$ & 44.9971 & $\checkmark$ \\
\hline & $\mathrm{H}_{2}^{13} \mathrm{CO}$ & 31.0134 & $\mathrm{CH}_{3} \mathrm{O}$ & 31.0178 & $\checkmark$ \\
\hline & ${ }^{13} \mathrm{CO}$ & 28.9977 & $\mathrm{CHO}$ & 29.0022 & $(\checkmark)$ \\
\hline \multirow[t]{6}{*}{${ }^{15} \mathrm{~N} /{ }^{14} \mathrm{~N}$} & ${ }^{15} \mathrm{NH}_{3}$ & 18.0230 & $\mathrm{NH}_{2} \mathrm{D}$ & 18.0323 & $(\checkmark)$ \\
\hline & $\mathrm{HC}^{15} \mathrm{~N}$ & 28.0074 & $\mathrm{~N}_{2}$ & 28.0056 & - \\
\hline & & & $\mathrm{H}^{13} \mathrm{CN}$ & 28.0137 & \\
\hline & $\mathrm{C}^{15} \mathrm{~N}$ & 26.9996 & ${ }^{13} \mathrm{CN}$ & 27.0059 & $(\checkmark)$ \\
\hline & ${ }^{15} \mathrm{NN}$ & 29.0026 & $\mathrm{CO}$ & 27.9944 & $(\checkmark)$ \\
\hline & & & $\mathrm{CHO}$ & 29.0022 & $(\checkmark)$ \\
\hline \multirow[t]{4}{*}{${ }^{17} \mathrm{O} /{ }^{16} \mathrm{O}$} & ${ }^{17} \mathrm{O}$ & 16.9986 & $\mathrm{OH}$ & 17.0022 & $?$ \\
\hline & $\mathrm{H}_{2}^{17} \mathrm{O}$ & 19.0142 & HDO & 19.0163 & $\checkmark$ \\
\hline & $\mathrm{C}^{17} \mathrm{O}$ & 28.9986 & ${ }^{13} \mathrm{CO}$ & 28.9977 & - \\
\hline & $\mathrm{CO}^{17} \mathrm{O}$ & 44.9935 & ${ }^{13} \mathrm{CO}_{2}$ & 44.9926 & $(\checkmark)$ \\
\hline \multirow[t]{4}{*}{${ }^{18} \mathrm{O} /{ }^{16} \mathrm{O}$} & ${ }^{18} \mathrm{O}$ & 17.9986 & $\mathrm{H}_{2} \mathrm{O}$ & 18.0100 & $\checkmark$ \\
\hline & $\mathrm{H}_{2}^{18} \mathrm{O}$ & 20.0143 & $\mathrm{HF}$ & 20.0057 & $\checkmark$ \\
\hline & $\mathrm{C}^{18} \mathrm{O}$ & 29.9986 & NO & 29.9974 & $?$ \\
\hline & $\mathrm{CO}^{18} \mathrm{O}$ & 45.9935 & $\mathrm{NO}_{2}$ & 45.9924 & $?$ \\
\hline \multirow[t]{2}{*}{${ }^{33} \mathrm{~S} /{ }^{32} \mathrm{~S}$} & ${ }^{33} \mathrm{~S}$ & 32.9709 & $\mathrm{HO}_{2}$ & 32.9971 & $\checkmark$ \\
\hline & $\mathrm{H}_{2}^{33} \mathrm{~S}$ & 34.9866 & $\mathrm{Cl}$ & 34.9683 & $\checkmark$ \\
\hline \multirow[t]{3}{*}{${ }^{34} \mathrm{~S} /{ }^{32} \mathrm{~S}$} & ${ }^{34} \mathrm{~S}$ & 33.9673 & $\mathrm{H}_{2} \mathrm{O}_{2}$ & 34.0049 & $\checkmark$ \\
\hline & $\mathrm{H}_{2}^{34} \mathrm{~S}$ & 35.9830 & $\mathrm{HCl}$ & 35.9761 & $\checkmark$ \\
\hline & & & ${ }^{36} \mathrm{Ar}$ & 35.967 & $(\checkmark)$ \\
\hline
\end{tabular}

$\checkmark$ : ROSINA will determine ratio, $(\checkmark)$ : determination is dependent on abundance, ?: not enough data available to make predictions, $(-)$ : ROSINA will not be able to determine the isotopic ratio

\subsubsection{Rosetta: COSAC and Ptolemy}

The Philae Lander (Bibring et al. 2007b) has two Gas Chromatography (GC)—Mass Spectrometer instruments, COSAC (Goesmann et al. 2007) and Ptolemy (Wright et al. 2007). 
The two instruments are complimentary in that COSAC aims to analyse the chemical composition of the organic compounds whereas Ptolemy aims to accurately measure the isotopic composition of the abundant chemical components, although there is some degree of overlap.

The Ptolemy mass spectrometer is an ion trap mass spectrometer (March and Todd 2005) with a mass range of 10 to $150 \mathrm{Da}$ and unit mass resolution. With a low resolution mass spectrometer separation of isobaric interferences directly by mass spectrometry is not possible. However, Ptolemy uses various chemical and gas chromatographic methods to separate the molecular species of interest. Ptolemy includes a reference gas reservoir so that aliquots can be processed and analysed in the same procedure as the sample gas to give a direct comparison with known terrestrial values. Reference gases processed through the Ptolemy GC system have shown that the precision for $\delta^{13} \mathrm{C}, \delta^{15} \mathrm{~N}$ and $\delta^{18} \mathrm{O}$ of approximately 20 permil can be achieved.

Comet samples can be collected by the Philae Lander Sampler Drill and Distribution system (SD2), from depths of up to 30cm (Finzi et al. 2007). These samples will be transferred into one of either 10 High Temperature Ovens (HTO), which have a maximum temperature of $\sim 600{ }^{\circ} \mathrm{C}$, or 16 Medium Temperature Ovens (MTO), which have a maximum temperature of $180^{\circ} \mathrm{C}$. The MTOs incorporate a window so that observations can be made of the sample by the CIVA microscopes (Bibring et al. 2007a) before and after heating. Samples are then heated in controlled temperature steps to evolve volatiles into the Ptolemy chemistry system. These gases will then be processed for isotopic analysis. One of the high temperature ovens contains a trapping material that passively collects coma gas when positioned in an exposed, low temperature position on the Lander balcony. The collected gas is then released into the Ptolemy system by heating the oven to $200^{\circ} \mathrm{C}$. Evolved gas will then be processed and analyzed in a similar way to the drill samples. This will allow a direct comparison of the coma composition at the Lander site and the Orbiter.

Usually a small aliquot of evolved gas is analyzed directly to obtain a bulk compositional mass spectrum. The processing that the sample undergoes is dependent on the required isotopic analysis. The various sample processing schemes are:

1. Organic composition. Injection of the sample into GC column A (30 m CP-Sil 8CB) which separates organic molecules to obtain chemical composition of organic molecules.

2. Carbon and nitrogen isotopic analysis. Injection of the sample into GC column B (30 $\mathrm{m}$ CP-PoraPLOT Q) which separates $\mathrm{CO}$ and $\mathrm{N}_{2}$ from $\mathrm{CO}_{2}$. As the sample elutes from the column it passes through a Rhodium oxide reactor which oxidises the $\mathrm{CO}$ to $\mathrm{CO}_{2}$. Isotopic exchange on the reactor gives the $\mathrm{CO}_{2}$ a terrestrial oxygen isotopic signature thus allowing accurate carbon isotopic analysis (Santrock et al. 1985).

3. Oxygen and hydrogen isotopic analysis of water. The water is reduced to $\mathrm{CO}$ and $\mathrm{H}_{2}$ by passing over a platinised carbon reactor which are then separated by GC column C (15 m 5 Angstroem molecular sieve MXT). Note that this is the only scheme which also gives a direct measurement of the ${ }^{17} \mathrm{O} /{ }^{16} \mathrm{O}$ ratio as well as the ${ }^{18} \mathrm{O} /{ }^{16} \mathrm{O}$ ratio.

4. Bulk hydrogen, carbon and nitrogen isotopic analysis. Combustion of the sample to $\mathrm{H}_{2} \mathrm{O}$, $\mathrm{CO}_{2}$ and $\mathrm{N}_{2}$. The carbon and nitrogen isotopes can then be analysed by either direct analysis or by using scheme (2) whilst water is analysed by scheme (3).

5. Noble gas analysis. Exposure of the sample to getters to remove all active gases to allow analysis of the noble gas concentrations and isotopic values.

6. Oxygen isotopic analysis of minerals. A reactor containing Asprey's salt (Asprey 1976) is heated to produce fluorine which is then used to liberate oxygen from the sample. Due to the reactive nature of this experiment this will be attempted near the end of the Lander mission. 
Table 7 Ptolemy measurements of isotopic ratios

\begin{tabular}{|c|c|c|c|}
\hline Species & Method & Isotope ratio & Requirements \\
\hline Bulk C & Combustion of solid sample to $\mathrm{CO}_{2}$ & ${ }^{13} \mathrm{C} /{ }^{12} \mathrm{C}$ & \\
\hline Bulk N & Combustion of solid sample to $\mathrm{N}_{2}$ & ${ }^{15} \mathrm{~N} /{ }^{14} \mathrm{~N}$ & \\
\hline Bulk H & $\begin{array}{l}\text { Combustion of solid sample to } \mathrm{H}_{2} \mathrm{O} \text { followed by reduction to } \\
\mathrm{CO} \text { and } \mathrm{H}_{2}\end{array}$ & $\mathrm{D} / \mathrm{H}$ & \\
\hline $\mathrm{H}_{2} \mathrm{O}$ & Reduction to $\mathrm{CO}$ and $\mathrm{H}_{2}$ (channel $\mathrm{C}$ ) & $\begin{array}{l}{ }^{18} \mathrm{O} /{ }^{16} \mathrm{O} \\
{ }^{17} \mathrm{O} /{ }^{16} \mathrm{O} \\
\mathrm{D} / \mathrm{H}\end{array}$ & \\
\hline \multirow[t]{2}{*}{$\mathrm{CO}_{2}$} & Direct analysis & $\begin{array}{l}{ }^{13} \mathrm{C} /{ }^{12} \mathrm{C} \\
{ }^{18} \mathrm{O} /{ }^{16} \mathrm{O}\end{array}$ & (2) \\
\hline & Channel B & ${ }^{13} \mathrm{C} /{ }^{12} \mathrm{C}$ & \\
\hline \multirow[t]{2}{*}{$\mathrm{CO}$} & Direct analysis & $\begin{array}{l}{ }^{13} \mathrm{C} /{ }^{12} \mathrm{C} \\
{ }^{18} \mathrm{O} /{ }^{16} \mathrm{O}\end{array}$ & $(1),(2)$ \\
\hline & Channel $\mathrm{B}$ oxidation to $\mathrm{CO}_{2}$ & ${ }^{13} \mathrm{C} /{ }^{12} \mathrm{C}$ & \\
\hline \multirow[t]{2}{*}{$\mathrm{CH}_{4}$} & $\begin{array}{l}\text { Removal } \mathrm{CO} \text { and } \mathrm{CO}_{2} \text { by getters, combustion to } \mathrm{CO}_{2} \text {, then } \\
\text { direct analysis }\end{array}$ & ${ }^{13} \mathrm{C} /{ }^{12} \mathrm{C}$ & \\
\hline & Channel $\mathrm{B}$, oxidation to $\mathrm{CO}_{2}$ & ${ }^{13} \mathrm{C} /{ }^{12} \mathrm{C}$ & \\
\hline \multirow[t]{2}{*}{$\mathrm{N}_{2}$} & Direct analysis & & (2) \\
\hline & Channel B, combustion to $\mathrm{N}_{2}$ & ${ }^{15} \mathrm{~N} /{ }^{14} \mathrm{~N}$ & \\
\hline $\mathrm{NH}_{3}$ & Channel $\mathrm{B}$, combustion to $\mathrm{N}_{2}$ & ${ }^{15} \mathrm{~N} /{ }^{14} \mathrm{~N}$ & \\
\hline Noble gases & Removal of active gases by getters & & \\
\hline Minerals & Reaction with fluorine, direct analysis & ${ }^{18} \mathrm{O} /{ }^{16} \mathrm{O}$ & \\
\hline
\end{tabular}

(1) ${ }^{13} \mathrm{C} /{ }^{12} \mathrm{C}$ measurement assumes $\delta^{17} \mathrm{O}$ - the terrestrial value within 200 permil

(2) Providing the $\mathrm{CO} / \mathrm{N}_{2}$ ratio is known

A summary of the various schemes and species targeted for isotopic analysis is shown in Table 7.

Ptolemy analysis of comet samples is a destructive technique that uses a relatively large amount of power and the target isotopic scheme has to be decided in advance and preprogrammed into the instrument. The planned First Science Sequence (FSS), which lasted from Lander touchdown until the non-rechargeable batteries were exhausted some 60 hours later, was to include the collection of 2 samples by SD2 from a depth of about $30 \mathrm{~cm}$ from the comet surface. Both samples were to be delivered to HTOs, one for Ptolemy and the other for COSAC. The aim of the Ptolemy experiment was to heat a sample in a HTO in four temperature steps using the following schemes; $-50{ }^{\circ} \mathrm{C}$ carbon and nitrogen isotopic analysis of $\mathrm{CO}$ and $\mathrm{N}_{2},+100{ }^{\circ} \mathrm{C}$ oxygen and hydrogen isotopic analysis of water, $+400{ }^{\circ} \mathrm{C}$ carbon and nitrogen isotopic analysis of $\mathrm{CO}, \mathrm{CO}_{2}$ and $\mathrm{N}_{2},+600^{\circ} \mathrm{C}$ bulk carbon and nitrogen isotopic analysis. This is then followed by a reference gas analysis.

Following a successful, but non-optimal landing, there was insufficient power for SD2 to collect a sample for Ptolemy. (SD2 did operate and attempted to collect a sample for COSAC, but it remains unknown whether or not a sample was delivered to the oven). The Ptolemy sequence was changed to a single isotopic analysis using the CASE oven in the 
hope that some material may have been collected during and after the landing. Although the sequence was successfully executed, the signal was too small to give meaningful isotope ratios.

The Long Term Science Sequence (LTS) was expected to start within a few weeks of the FSS where recharging of the Philae secondary batteries would allow intermittent operations for up to six months. In the current configuration it is hoped that the Lander will have sufficient power to begin operations in spring 2015. Ptolemy operation is severely restricted by power resources, however during the LTS the composition of the sample before analysis will be better characterized including ROLIS and CIVA imaging and ongoing observations from orbiter instruments e.g. ROSINA. The Ptolemy aim is to target particular abundant species for isotopic analysis, make coma observations using the adsorbent oven as the comet becomes more active and finally attempt a fluorination of the refractory residue from a High Temperature Oven.

\subsubsection{MIRO}

The main goals of the Microwave Instrument for the Rosetta Orbiter (MIRO) are to measure the thermal emission from nucleus sub-surface layers in two continuum channels $(0.5$ and $1.6 \mathrm{~mm}$ ), and to characterize the outgassing of four fundamental molecules $\left(\mathrm{H}_{2} \mathrm{O}, \mathrm{CO}, \mathrm{NH}_{3}\right.$, $\mathrm{CH}_{3} \mathrm{OH}$ ) from their lines near $0.5 \mathrm{~mm}$ (Gulkis et al. 2007). The fundamental rotational lines $1_{10}-1_{01}$ of the three oxygen-related isotopologues of water $\left(\mathrm{H}_{2}^{16} \mathrm{O}, \mathrm{H}_{2}^{18} \mathrm{O}\right.$, and $\left.\mathrm{H}_{2}^{17} \mathrm{O}\right)$ are observed simultaneously to determine the ${ }^{18} \mathrm{O} /{ }^{16} \mathrm{O}$ and ${ }^{17} \mathrm{O} /{ }^{16} \mathrm{O}$ ratios.

\subsection{Measurements from Ground-Based and Space-Based Facilities}

The Atacama Large Millimeter/submillimeter Array is currently under construction in northern Chile's Atacama desert at an altitude of 5000 meters above sea level. The ALMA interferometer will initially be composed of 66 antennas working at millimeter and submillimeter wavelengths (Wootten 2008). ALMA signifies the beginning of a new era for cometary science, in which routine measurements of the three-dimensional distributions of molecular species are now possible for almost all comets, with visual magnitudes of 8 or brighter. For the brightest comets, it will be possible to detect molecules which have strong lines in the microwave range, such as $\mathrm{HDO}, \mathrm{DCN}, \mathrm{H}^{13} \mathrm{CN}, \mathrm{HC}^{15} \mathrm{~N}, \mathrm{H}^{15} \mathrm{NC}, \mathrm{H}_{2}^{34} \mathrm{~S}$, and $\mathrm{C}^{34} \mathrm{~S}$, isotopes of $\mathrm{CH}_{3} \mathrm{OH}$, etc. Hence, it will be possible to probe the isotopic diversity in the comet population. The prospects for ALMA observations of comets are discussed by Biver (2005) and Bockelée-Morvan (2008).

The upcoming of 40-m class optical telescopes will ease the characterization of deuterium fraction in water and methane in comets. At the European Extremely Large telescope (E-ELT) built by the European Southern Observatory, high-resolution spectroscopy in the L and $\mathrm{M}$ near-IR bands will be offered by one of the first generation instruments ELT-MIR.

\subsection{On the Analyses of Cometary Samples on Earth}

Samples of Comet 81P/Wild 2 returned by the Stardust mission are continuously being analyzed. Indigenous organic compounds recovered from this samples may include potential prebiotic compounds like glycine (Elsila et al. 2009). Further improvement in laboratory techniques may enable the measurement of the isotopic compositions of these compounds in order to ascertain their indigenous origin. In the coming year, with the forthcoming return of samples from primitive asteroids (Hayabusa 2 and Osiris-Rex missions), more constraints 
will be available on the relationship between primitive asteroids and carbonaceous chondrites (CI, CM, CR) that are suspected of having a cometary origin. The origin of GEMS in CP-IDPs is still debated, as some of these glassy inclusions (the largest ones) show isotopic anomalies possibly related to a presolar heritage, although their collection in silicon oil may bias the analyses (Bradley 2013; Keller and Messenger 2013). By contrast, UCAMMs are collected in water and do not suffer such bias. Analyzing the oxygen isotopic composition of GEMS in UCAMMs should provide more clues on the origin of these phases that seem ubiquitous in cometary material. UCAMMs offer an opportunity to directly study the association of organics and minerals in primitive dust. Measuring both the hydrogen and nitrogen isotopic compositions of organic matter in UCAMMs will shed more light on the formation and evolution of organic matter in the solar system (e.g., Floss et al. 2012; Haenecour et al. 2014; Bardin et al. 2014; Duprat et al. 2014). Since UCAMMs did not endure substantial alteration at atmospheric entry or during their stay in the snow, their content in presolar grains should also provide a valuable constraint on the interstellar heritage in cometary solids.

\section{Summary}

In this chapter, we reviewed the isotopic composition of cometary volatiles and grains, as well as that of potential cometary material available in collections on Earth. We discussed the isotopic ratios in the light of processes governing interstellar fractionation. Comparing isotopic ratios in comets and planets can shed light to the origin of volatiles in planets, as discussed in Mandt et al. (2015, this issue).

Important progresses in our knowledge of comet composition will benefit from current or future space missions to comets (e.g., the Rosetta mission of ESA) and from telescopic observations with yet available or new instrumentation (e.g., ALMA). Our understanding of comet composition in the context of the origin and evolution of our Solar System will greatly benefit from theoretical models of chemical and physical processes in the solar nebula, and from upcoming new results on the composition of protostellar sources and protoplanetary disks at different stages of evolution.

Acknowledgements This work was supported by NASA's Planetary Astronomy and Planetary Atmospheres Programs (SNM and SBC), and by the Swedish Space Board (ESW).

\section{References}

P. Ábrahám et al., Episodic formation of cometary material in the outburst of a young Sun-like star. Nature 459, 224-226 (2009)

N.G. Adams, D. Smith, ${ }^{14} \mathrm{~N} /{ }^{15} \mathrm{~N}$ isotope fractionation in the reaction $\mathrm{N}_{2} \mathrm{H}^{+}+\mathrm{N}_{2}$-interstellar significance. Astrophys. J. 247, L123-L125 (1981)

Y. Aikawa, E. Herbst, Deuterium fractionation in protoplanetary disks. Astrophys. J. 526, 314-326 (1999)

J. Aléon, Multiple origins of nitrogen isotopic anomalies in meteorites and comets. Astrophys. J. 72, 13421351 (2010)

C.M.O.D. Alexander, R. Bowden, M.L. Fogel, K.T. Howard, C.D.K. Herd, L.R. Nittler, The provenances of asteroids, and their contributions to the volatile inventories of the terrestrial planets. Science 337(6095), 721-723 (2012)

K. Altwegg, Habilitationsschrift. University of Bern (1996)

K. Altwegg et al., 67P/Churyumov-Gerasimenko, a Jupiter family comet with a high D/H ratio. Science 347, 1261952 (2014)

E. Anders, Do stony meteorites come from comets? Icarus 24, 363-371 (1975)

E. Anders, N. Grevesse, Abundances of the elements-meteoritic and solar. Geochim. Cosmochim. Acta 53, 197-214 (1989) 
C. Arpigny, E. Jehin, J. Manfroid, D. Hutsemékers, R. Schulz, J.A. Stüwe, J.-M. Zucconi, I. Ilyin, Anomalous nitrogen isotope ratio in comets. Science 301, 1522-1525 (2003)

L.B. Asprey, The preparation of very pure fluorine gas. J. Fluorine Chem. 7, 359-361 (1976)

J. Bally, W.D. Langer, Isotope-selective photodestruction of carbon monoxide. Astrophys. J. 255, $143-148$ (1982)

H. Balsiger, K. Altwegg, J. Geiss, D/H and ${ }^{18} \mathrm{O} /{ }^{16} \mathrm{O}$ ratio in the hydronium ion and in neutral water from in situ ion measurements in comet P/Halley. J. Geophys. Res. 100, 5827-5834 (1995)

H. Balsiger et al., ROSINA-Rosetta Orbiter Spectrometer for Ion and Neutral Analysis. Space Sci. Rev. 128, 745-801 (2007)

N. Bardin, G. Slodzian, T.-D. Wu, D. Baklouti, E. Dartois, C. Engrand, R. Brunetto, J.-L. Guerquin-Kern, J. Duprat, D/H measurements in ultracarbonaceous antarctic micrometeorites using polyatomic ions with SIMS. Lunar Planet. Sci. Conf. Abstr. 45, 2647 (2014)

E.A. Bergin et al., Herschel observations of EXtra-Ordinary Sources (HEXOS): the present and future of spectral surveys with Herschel/HIFI. Astron. Astrophys. 521, L20-L27 (2010)

J.-P. Bibring, P. Lamy, Y. Langevin, A. Soufflot, M. Berthé, J. Borg, F. Poulet, S. Mottola, CIVA. Space Sci. Rev. 128, 363-381 (2007a)

J.-P. Bibring, H. Rosenbauer, H. Boehnhardt, S. Ulamec, J. Biele, S. Espinasse, B. Feuerbacher, P. Gaudon, P. Hemmerich, P. Kletzkine, D. Moura, R. Mugnuolo, G. Nietner, B. Pätz, R. Roll, H. Scheuerle, K. Szegö, K. Wittmann (Philae Team), Rosetta lander ("Philae") investigations. Space Sci. Rev. 128, 205220 (2007b)

N. Biver, Comets with ALMA. ESA SP 577, 151-156 (2005)

N. Biver, D. Bockelée-Morvan, J. Crovisier, D.C. Lis, R. Moreno, P. Colom, F. Henry, F. Herpin, G. Paubert, M. Womack, Radio wavelength molecular observations of comets C/1999 T1 (McNaught-Hartley), C/2001 A2 (LINEAR), C/2000 WM 1 (LINEAR) and 153P/Ikeya-Zhang. Astron. Astrophys. 449, 1255-1270 (2006)

N. Biver, D. Bockelée-Morvan, J. Crovisier, A. Lecacheux, U. Frisk, Å. Hjalmarson, M. Olberg, H.-G. Florén, A. Sandqvist, S. Kwok, Submillimetre observations of comets with Odin: 2001-2005. Planet. Space Sci. 55, 1058-1068 (2007)

N. Biver et al., Composition and Outburst Follow-up Observations of Comet 17P/Holmes at the Nançay, IRAM and CSO Radio Observatories. LPI Contributions, vol. 1405 (2008), p. 8146

N. Biver et al., Ammonia and other parent molecules in comet 10P/Tempel 2 from Herschel/HIFI and groundbased radio observations. Astron. Astrophys. 539, 68 (2012)

L. Bizzocchi, P. Caselli, E. Leonardo, L. Dore, Detection of ${ }^{15} \mathrm{NNH}^{+}$in L1544: non-LTE modelling of dyazenilium hyperfine line emission and accurate ${ }^{14} \mathrm{~N} /{ }^{15} \mathrm{~N}$ values. Astron. Astrophys. 555, A109A120 (2013)

L. Bizzocchi, P. Caselli, S. Spezzano, E. Leonardo, Deuterated methanol in the pre-stellar core L1544. Astron. Astrophys. 569, A27-A34 (2014)

G.A. Blake, E.C. Sutton, C.R. Masson, T.G. Phillips, Molecular abundances in OMC-1-the chemical composition of interstellar molecular clouds and the influence of massive star formation. Astrophys. J. 315, 621-645 (1987)

G.A. Blake, C. Qi, M.R. Hogerheijde, M.A. Gurwell, D.O. Muhleman, Sublimation from icy jets as a probe of the interstellar volatile content of comets. Nature 398, 213-216 (1999)

D. Bockelée-Morvan, Cometary science with ALMA. Astrophys. Space Sci. 313, 183-189 (2008)

D. Bockelée-Morvan, An overview of comet composition, in The Molecular Universe, ed. by J. Cernicharo, R. Bachiller. IAU Symposium, vol. 280 (Cambridge University press, Cambridge, 2011), pp. 261-274

D. Bockelée-Morvan et al., Deuterated water in comet C/1996 B2 (Hyakutake) and its implications for the origin of comets. Icarus 133, 147-162 (1998)

D. Bockelée-Morvan et al., New molecules found in comet C/1995 O1 (Hale-Bopp). Investigating the link between cometary and interstellar material. Astron. Astrophys. 353, 1101-1114 (2000)

D. Bockelée-Morvan, D. Gautier, F. Hersant, J.-M. Huré, F. Robert, Turbulent radial mixing in the solar nebula as the source of crystalline silicates in comets. Astron. Astrophys. 384, 1107-1118 (2002)

D. Bockelée-Morvan, N. Biver, E. Jehin, A.L. Cochran, H. Wiesemeyer, J. Manfroid, D. Hutsemékers, C. Arpigny, J. Boissier, W. Cochran, P. Colom, J. Crovisier, N. Milutinovic, R. Moreno, J.X. Prochaska, I. Ramirez, R. Schulz, J.-M. Zucconi, Large excess of heavy nitrogen in both hydrogen cyanide and cyanogen from comet 17P/Holmes. Astrophys. J. 679, L49-L52 (2008)

D. Bockelée-Morvan et al., Herschel measurements of the $\mathrm{D} / \mathrm{H}$ and ${ }^{16} \mathrm{O} /{ }^{18} \mathrm{O}$ ratios in water in the Oort-cloud comet C/2009 P1 (Garradd). Astron. Astrophys. 544, L15 (2012)

B.P. Bonev, M.J. Mumma, E.L. Gibb, M.A. DiSanti, G.L. Villanueva, K. Magee-Sauer, R.S. Ellis, Comet C/2004 Q2 (Machholz): parent volatiles, a search for deuterated methane, and constraint on the $\mathrm{CH}_{4}$ spin temperature. Astrophys. J. 699, 1563-1572 (2009) 
T.L. Bourke, P.C. Myers, N.J. Evans II., M.M. Dunham, J. Kauffmann, Y.L. Shirley, A. Crapsi, C.H. Young, T.L. Huard, T.Y. Brooke, N. Chapman, L. Cieza, C.W. Lee, P. Teuben, Z. Wahhaj, The Spitzer c2d survey of nearby dense cores. II. Discovery of a low-luminosity object in the "Evolved Starless Core" L1521F. Astrophys. J. 649, L37-L40 (2006)

J.P. Bradley, Interplanetary dust particles, in Meteorites, Comets and Planets: Treatise on Geochemistry, ed. by A.M. Davis, H.D. Holland, K.K. Turekian (Elsevier/Pergamon, Oxford, 2005), pp. 689-711

J.P. Bradley, How and where did gems form? Geochim. Cosmochim. Acta 107(0), 336-340 (2013)

J.P. Bradley, D.E. Brownlee, Cometary particles - thin sectioning and electron beam analysis. Science 231, 1542-1544 (1986)

R. Brasser, A. Morbidelli, Oort cloud and scattered disc formation during a late dynamical instability in the solar system. Icarus 225, 40-49 (2013)

G. Briani, M. Gounelle, Y. Marrocchi, S. Mostefaoui, H. Leroux, E. Quirico, A. Meibom, Pristine extraterrestrial material with unprecedented nitrogen isotopic variation. Proc. Nat. Acad. Sci. 106, 10522-10527 (2009)

J.C. Bridges, H.G. Changela, S. Nayakshin, N.A. Starkey, I.A. Franchi, Chondrule fragments from Comet Wild 2: evidence for high temperature processing in the outer solar system. Earth Planet. Sci. Lett. 341, 186-194 (2012)

R.H. Brown, D.S. Lauretta, B. Schmidt, J. Moores, Experimental and theoretical simulations of ice sublimation with implications for the chemical, isotopic, and physical evolution of icy objects. Planet. Space Sci. 60, 166-180 (2012)

D.E. Brownlee, Cosmic dust: collection and research. Annu. Rev. Earth Planet. Sci. 13, 147-173 (1985)

D. Brownlee, The stardust mission: analyzing samples from the edge of the solar system. Annu. Rev. Earth Planet. Sci. 42, 179-205 (2014)

D.E. Brownlee, D.J. Joswiak, D.J. Schlutter, R.O. Pepin, J.P. Bradley, S.G. Love, Identification of individual cometary IDPs by thermally stepped He release, in Lunar Planet. Sci., vol. XXVI (1995), pp. 183-184

D.E. Brownlee et al., Stardust: comet and interstellar dust sample return mission. J. Geophys. Res., Planets 108, 8111 (2003)

D.E. Brownlee et al., Surface of young Jupiter family comet 81 P/Wild 2: view from the Stardust Spacecraft. Science 304, 1764-1769 (2004)

D. Brownlee et al., Comet 81P/Wild 2 under a microscope. Science 314, 1711-1716 (2006)

R. Brunetto, J. Borg, E. Dartois, F.J.M. Rietmeijer, F. Grossemy, C. Sandt, L. Le Sergeant d'Hendecourt, A. Rotundi, P. Dumas, Z. Djouadi, F. Jamme, Mid-IR, Far-IR, Raman micro-spectroscopy, and FESEMEDX study of IDP L2021C5: clues to its origin. Icarus 212(2), 896-910 (2011)

H. Busemann, A.F. Young, C.M.O.D. Alexander et al., Interstellar chemistry recorded in organic matter from primitive meteorites. Science 312, 727-730 (2006)

H. Busemann, A.N. Nguyen, G.D. Cody, P. Hoppe, A.L.D. Kilcoyne, R.M. Stroud, T.J. Zega, L.R. Nittler, Ultra-primitive interplanetary dust particles from the comet 26P/Grigg-Skjellerup dust stream collection. Earth Planet. Sci. Lett. 288(1-2), 44-57 (2009)

H. Campins, T.D. Swindle, Expected characteristics of cometary meteorites. Meteorit. Planet. Sci. 33, 12011211 (1998)

C. Ceccarelli, P. Caselli, D. Bockelée-Morvan, O. Mousis, S. Pizzarello, F. Robert, D. Semenov, Deuterium fractionation: the Ariadne's thread from the pre-collapse phase to meteorites and comets today, in Protostars and Planets VI, ed. by H. Beuther, R. Klessen, C. Dullemond, Th. Henning (University of Arizona Press, Tucson, 2014), pp. 859-882

S.B. Charnley, S.D. Rodgers, The end of interstellar chemistry as the origin of nitrogen in comets and meteorites. Astrophys. J. 569, L133-L137 (2002)

S.B. Charnley, S.D. Rodgers, Interstellar reservoirs of cometary matter. Space Sci. Rev. 138, 59-73 (2008)

S.B. Charnley, A.G.G.M. Tielens, S.D. Rodgers, Deuterated methanol in the Orion compact ridge. Astrophys. J. 482, L203-L206 (1997)

S.B. Charnley, P. Ehrenfreund, T.J. Millar, A.C.A. Boogert, A.J. Markwick, H.M. Butner, R. Ruiterkamp, S.D. Rodgers, Observational tests for grain chemistry: posterior isotopic labeling. Mon. Not. R. Astron. Soc. 347, 157-162 (2004)

L.I. Cleeves, E.A. Bergin, C.M.O.D. Alexander, F. Du, D. Graninger, K.I. Öberg, T.J. Harries, The ancient heritage of water ice in the solar system. Science 345, 1590-1593 (2014)

A. Cochran, A.-C. Levasseur-Regourd, M. Cordiner, E. Hadamcik, J. Lasue, A. Gicquel, D.G. Schleicher, S.B. Charnley, M.J. Mumma, L. Paganini, D. Bockelée-Morvan, N. Biver, Y.-J. Kuan, The composition of comets: a pre-Rosetta look. Space Sci. Rev. (2015, this issue)

J. Crovisier, D. Bockelée-Morvan, P. Colom, N. Biver, D. Despois, D.C. Lis (The Team for Target-ofOpportunity Radio Observations of Comets), The composition of ices in comet C/1995 O1 (Hale-Bopp) from radio spectroscopy. Further results and upper limits on undetected species. Astron. Astrophys. 418, 1141-1157 (2004) 
F. Daniel, M. Gérin, E. Roueff, J. Cernicharo, N. Marcelino, F. Lique, D.C. Lis, D. Teyssier, N. Biver, D. Bockelée-Morvan, Nitrogen isotopic ratios in Barnard 1: a consistent study of the $\mathrm{N}_{2} \mathrm{H}^{+}, \mathrm{NH}_{3}, \mathrm{CN}$, HCN, and HNC isotopologues. Astron. Astrophys. 560, AA3 (2013)

A.C. Danks, D.L. Lambert, C. Arpigny, The ${ }^{12} \mathrm{C} /{ }^{13} \mathrm{C}$ ratio in comet Kohoutek 1973f. Astrophys. J. 194, 745-751 (1974)

E. Dartois, C. Engrand, R. Brunetto, J. Duprat, T. Pino, E. Quirico, L. Remusat, N. Bardin, G. Briani, S. Mostefaoui, G. Morinaud, B. Crane, N. Szwec, L. Delauche, F. Jamme, C. Sandt, P. Dumas, Ultracarbonaceous antarctic micrometeorites, probing the solar system beyond the nitrogen snow-line. Icarus 224(1), 243-252 (2013)

J. Davidson, H. Busemann, I.A. Franchi, A NanoSIMS and Raman spectroscopic comparison of interplanetary dust particles from comet Grigg-Skjellerup and non-Grigg Skjellerup collections. Meteorit. Planet. Sci. 47, 1748-1771 (2012)

A. Decock, E. Jehin, P. Rousselot, D. Hutsemékers, J. Manfroid, D. Cordier, in International Comet Workshop, April 1-3, 2014, Toulouse, France (2014)

E. Dobrică, C. Engrand, E. Quirico, G. Montagnac, J. Duprat, Raman characterization of carbonaceous matter in concordia antarctic micrometeorites. Meteorit. Planet. Sci. 46(9), 1363-1375 (2011)

E. Dobrică, C. Engrand, H. Leroux, J.N. Rouzaud, J. Duprat, Transmission electron microscopy of concordia ultracarbonaceous antarctic micrometeorites (UCAMMs): mineralogical properties. Geochim. Cosmochim. Acta 76, 68-82 (2012)

L. Dones, P.R. Weissman, H.F. Levison, M.J. Duncan, Oort cloud formation and dynamics, in Comets II, ed. by M.C. Festou et al., (University of Arizona Press, Tucson, 2004), pp. 153-174

K. Dressler, D.A. Ramsay, The electronic absorption spectra of $\mathrm{NH}_{2}$ and $\mathrm{ND}_{2}$. Philos. Trans. R. Soc. Lond. A 251, 553-602 (1959)

J. Duprat, E. Dobrica, C. Engrand, J. Aléon, Y. Marrocchi, S. Mostefaoui, A. Meibom, H. Leroux, J.N. Rouzaud, M. Gounelle, F. Robert, Extreme deuterium excesses in ultracarbonaceous micrometeorites from central antarctic snow. Science 328(5979), 742-745 (2010)

J. Duprat, N. Bardin, C. Engrand, D. Baklouti, R. Brunetto, E. Dartois, L. Delauche, M. Godard, G. Slodzian, T.-D. Wu, J.-L. Guerkin-Kern, Isotopic analysis of organic matter in ultra-carbonaceous micrometeorites. Meteorit. Planet. Sci. 49(S1), A103 (2014)

P. Eberhardt, R. Meier, D. Krankowsky, R.R. Hodges, Methanol and hydrogen sulfide in comet P/Halley. Astron. Astrophys. 288, 315-329 (1994)

P. Eberhardt, M. Reber, D. Krankowsky, R.R. Hodges, The D/H and ${ }^{18} \mathrm{O} /{ }^{16} \mathrm{O}$ ratios in water from comet P/Halley. Astron. Astrophys. 302, 301-316 (1995)

J.E. Elsila, D.P. Glavin, J.P. Dworkin, Cometary glycine detected in samples returned by Stardust. Meteorit. Planet. Sci. 44, 1323-1330 (2009)

G.B. Esplugues, J. Cernicharo, S. Viti, J.R. Goicoechea, B. Tercero, N. Marcelino, A. Palau, T.A. Bell, E.A. Bergin, N.R. Crockett, S. Wang, Combined IRAM and Herschel/HIFI study of cyano(di)acetylene in Orion KL: tentative detection of $\mathrm{DC}_{3} \mathrm{~N}$. Astron. Astrophys. 559, A51 (2013)

A.E. Finzi, F.B. Zazzera, C. Dainese, F. Malnati, P.G. Magnani, E. Re, P. Bologna, S. Espinasse, A. Olivieri, SD2-how to sample a comet. Space Sci. Rev. 128, 281-299 (2007)

C. Floss, F.J. Stadermann, J.P. Bradley, Z.R. Dai, S. Bajt, G. Graham, A.S. Lea, Identification of isotopically primitive interplanetary dust particles: a NanoSIMS isotopic imaging study. Geochim. Cosmochim. Acta 70, 2371-2399 (2006)

C. Floss, T. Noguchi, T. Yada, Ultracarbonaceous antarctic micrometeorites: origins and relationships to other primitive extraterrestrial materials, in Lunar and Planetary Science Conference, vol. 43 (2012), p. 1217

C. Floss, F.J. Stadermann, A.T. Kearsley, M.J. Burchell, W.J. Ong, The abundance of presolar grains in comet 81P/Wild 2. Astrophys. J. 763(2), 140-151 (2013)

F. Fontani, T. Sakai, K. Furuya, N. Sakai, Y. Aikawa, S. Yamamoto, DNC/HNC and $\mathrm{N}_{2} \mathrm{D}^{+} / \mathrm{N}_{2} \mathrm{H}^{+}$ratios in high-mass star-forming cores. Mon. Not. R. Astron. Soc. 440, 448-456 (2014)

T. Fouchet, P.G.J. Irwin, P. Parrish, S.B. Calcutt, F.W. Taylor, C.A. Nixon, T. Owen, Search for spatial variation in the jovian ${ }^{15} \mathrm{~N} /{ }^{14} \mathrm{~N}$ ratio from Cassini/CIRS observations. Icarus 172, 50-58 (2004)

J. Geiss, G. Gloeckler, Abundances of deuterium and Helium-3 in the protosolar cloud. Space Sci. Rev. 84, 239-250 (1998)

M. Gérin, N. Marcelino, N. Biver, E. Roueff, L.H. Coudert, M. Elkeurti, D.C. Lis, D. Bockelé-Morvan, Detection of ${ }^{15} \mathrm{NH}_{2} \mathrm{D}$ in dense cores: a new tool for measuring the ${ }^{14} \mathrm{~N} /{ }^{15} \mathrm{~N}$ ratio in the cold ISM. Astron. Astrophys. 498, L9-L12 (2009)

E.L. Gibb, B.P. Bonev, G. Villanueva, M.A. DiSanti, M.J. Mumma, E. Sudholt, Y. Radeva, Chemical composition of comet C/2007 N3 (Lulin): another "Atypical" comet. Astrophys. J. 750, 102-115 (2012)

A. Gicquel, S.N. Milam, G.L. Villanueva, A.J. Remijan, I.M. Coulson, Y.-L. Chuang, S.B. Charnley, M.A. Cordiner, Y.-J. Kuan, Ground-based multiwavelength observations of comet 103P/Hartley 2. Astrophys. J. 794, 1-10 (2014) 
K. Giles, N.G. Adams, D. Smith, A study of the reactions of $\mathrm{H}_{3}^{+}, \mathrm{H}_{2} \mathrm{D}^{+}, \mathrm{HD}_{2}^{+}$, and $\mathrm{D}_{3}^{+}$with $\mathrm{H}_{2}, \mathrm{HD}, \mathrm{D}_{2}$ using a variable-temperature selected ion flow tube. J. Phys. Chem. 96, 7645 (1992)

F. Goesmann, H. Rosenbauer, R. Roll, C. Szopa, F. Raulin, R. Sternberg, G. Israel, U. Meierhenrich, W. Thiemann, G. Munoz-Caro, COSAC, the COmetary SAmpling and Composition experiment on Philae. Space Sci. Rev. 128, 257-280 (2007)

M. Gounelle, P. Spurny, P.A. Bland, The orbit and atmospheric trajectory of the orgueil meteorite from historical records. Meteorit. Planet. Sci. 41, 135-150 (2006)

J.M. Greenberg, What are comets made of - a model based on interstellar dust, in Comet Discoveries, Statistics, and Observational Selection. IAU Colloq., vol. 61 (1982), pp. 131-163

S. Gulkis et al., Remote sensing of a comet at millimeter and submillimeter wavelengths from an orbiting spacecraft. Planet. Space Sci. 55, 1050-1057 (2007)

H. Haack, R. Michelsen, G. Stober, D. Keuer, W. Singer, I. Williams, CM Chondrites from Comets? New Constraints from the Orbit of the Maribo CM Chondrite Fall LPI Contributions, vol. 1639 (2011), p. 9100

P. Haenecour, C. Floss, A. Wang, T. Yada, Coordinated Analysis of Isotopic Anomalies in Antarctic Micrometeorites. LPI Contributions, vol. 1783 (2014), p. 5017

M.S. Hanner, M.E. Zolensky, The mineralogy of cometary dust, in Astromineralogy, ed. by T. Henning (Springer, Berlin, 2010), pp. 203-226

D.E. Harker, S.J. Desch, Annealing of silicate dust by nebular shocks at 10 AU. Astrophys. J. 565, L109L112 (2002)

P. Hartogh et al., Ocean-like water in the Jupiter-family comet 103P/Hartley 2. Nature 478, 218-220 (2011)

M. Hässig, K. Altwegg, H. Balsiger, J.J. Berthelier, U. Calmonte, M. Combi, J. De Keyser, B. Fiethe, S.A. Fuselier, M. Rubin, ROSINA/DFMS capabilities to measure isotopic ratios in water at comet 67P/Churyumov-Gerasimenko. Planet. Space Sci. 84, 148-152 (2013)

A.N. Heays, R. Visser, R. Gredel, W. Ubachs, B.R. Lewis, S.T. Gibson, E.F. van Dishoeck, Isotope selective photodissociation of $\mathrm{N}_{2}$ by the interstellar radiation field and cosmic rays. Astron. Astrophys. 562, A61 (2014)

E. Herbst, E.F. van Dishoeck, Complex organic interstellar molecules. Annu. Rev. Astron. Astrophys. 47, 427-480 (2009)

F. Hersant, D. Gautier, J.-M. Huré, A two-dimensional model for the primordial nebula constrained by D/H measurements in the solar system: implications for the formation of giant planets. Astrophys. J. 554, 391-407 (2001)

P. Hily-Blant, L. Bonal, A. Faure, E. Quirico, The ${ }^{15} \mathrm{~N}$-enrichment in dark clouds and solar system objects. Icarus 223, 582-590 (2013a)

P. Hily-Blant, G. Pineau des Forêts, A. Faure, R. Le Gal, M. Padovani, The $\mathrm{CN} / \mathrm{C}^{15} \mathrm{~N}$ isotopic ratio towards dark clouds. Astron. Astrophys. 557, A65 (2013b)

D.A. Howe, T.J. Millar, P. Schilke, C.M. Walmsley, Observations of deuterated cyanoacetylene in dark clouds. Mon. Not. R. Astron. Soc. 267, 59-68 (1994)

W.F. Huebner, J.J. Keady, S.P. Lyon, Solar photorates for planetary atmospheres and atmospheric pollutants. Astrophys. Space Sci. 195, 1-289 (1992)

D. Hutsemékers, J. Manfroid, E. Jehin, C. Arpigny, A. Cochran, R. Schulz, J.A. Stüwe, J.-M. Zucconi, Isotopic abundances of carbon and nitrogen in Jupiter-family and Oort-cloud comets. Astron. Astrophys. 440, 21-24 (2005)

D. Hutsemékers, J. Manfroid, E. Jehin, J.-M. Zucconi, C. Arpigny, The ${ }^{16} \mathrm{OH} /{ }^{18} \mathrm{OH}$ and OD/OH isotope ratios in comet C/2002 T7 (LINEAR). Astron. Astrophys. 490, L31-L34 (2008)

M. Ikeda, T. Hirota, S. Yamamoto, The $H^{13} \mathrm{CN} / \mathrm{HC}^{15} \mathrm{~N}$ abundance ratio in dense cores: possible source-tosource variation of isotope abundances? Astrophys. J. 575, 250-256 (2002)

H.A. Ishii, J.P. Bradley, Z.R. Dai, M. Chi, A.T. Kearsley, M.J. Burchell, N.D. Browning, F. Molster, Comparison of comet 81P/Wild 2 dust with interplanetary dust from comets. Science 319, 447-450 (2008)

E. Jacquet, F. Robert, Water transport in protoplanetary disks and the hydrogen isotopic composition of chondrites. Icarus 223, 722-732 (2013)

E. Jehin, J. Manfroid, A.L. Cochran, C. Arpigny, J.-M. Zucconi, D. Hutsemékers, W.D. Cochran, M. Endl, R. Schulz, The anomalous ${ }^{14} \mathrm{~N} /{ }^{15} \mathrm{~N}$ ratio in comets 122P/1995 S1 (de Vico) and 153P/2002 C1 (IkeyaZhang). Astrophys. J. 613, 161-164 (2004)

E. Jehin, J. Manfroid, D. Hutsemékers, A.L. Cochran, C. Arpigny, W.M. Jackson, H. Rauer, R. Schulz, J.-M. Zucconi, Deep impact: high-resolution optical spectroscopy with the ESO VLT and the Keck I telescope. Astrophys. J. 641, 145-148 (2006)

E. Jehin, J. Manfroid, D. Hutsemékers, C. Arpigny, J.-M. Zucconi, Isotopic ratios in comets: status and perspectives. Earth Moon Planets 105, 167-180 (2009) 
E. Jehin, D. Hutsemékers, J. Manfroid, A. Decock, M. Weiler, H. Kawakita, Y. Shinnaka, M. Hashimoto, D. Bockelée-Morvan, N. Biver, J. Crovisier, P. Hartogh, in EPSC-DPS Joint Meeting 2011, October 2-7, 2011 Nantes, France (2011), p. 1463

E. Jehin, J. Manfroid, H. Kawakita, D. Hutsemékers, M. Weiler, C. Arpigny, A. Cochran, O. Hainaut, H. Rauer, R. Schulz, J.-M. Zucconi, Optical spectroscopy of the B and C fragments of comet 73P/Schwassmann-Wachmann 3 at the ESO VLT, in Asteroids, Comets, Meteors 2008, July 14-18, 2008, Baltimore, Maryland. LPI Contributions, vol. 1405, p. 8319 (2008)

E.K. Jessberger, J. Kissel, Chemical properties of cometary dust and a note on carbon isotopes, in Comets in the Post-Halley Era 167, IAU Colloq., vol. 116 (1991), pp. 1075-1092

D. Jewitt, H.E. Matthews, T. Owen, R. Meier, Measurements of ${ }^{12} \mathrm{C} /{ }^{13} \mathrm{C},{ }^{14} \mathrm{~N} /{ }^{15} \mathrm{~N}$, and ${ }^{32} \mathrm{~S} /{ }^{34} \mathrm{~S}$ ratios in comet Hale-Bopp (C/1995 O1). Science 278, 90-93 (1997)

J.K. Jørgensen, F.L. Schöier, E.F. van Dishoeck, Molecular inventories and chemical evolution of low-mass protostellar envelopes. Astron. Astrophys. 416, 603-622 (2004)

Y. Kakazu, C. Engrand, J. Duprat, G. Briani, N. Bardin, S. Mostefaoui, R. Duhamel, L. Remusat, Bulk oxygen isotopic composition of utracarbonaceous antarctic micrometeorites with the nanosims. Meteorit. Planet. Sci. 49(S1), A195 (2014)

J.J. Kavelaars, O. Mousis, J.-M. Petit, H.A. Weaver, On the formation location of Uranus and Neptune as constrained by dynamical and chemical models of comets. Astrophys. J. 734, LL30 (2011)

H. Kawakita, H. Kobayashi, Formation conditions of icy materials in comet C/2004 Q2 (Machholz). II. Diagnostics using nuclear spin temperatures and deuterium-to-hydrogen ratios in cometary molecules. Astrophys. J. 693, 388-396 (2009)

H. Kawakita, J.-I. Watanabe, Fluorescence efficiencies of monodeuterio-methane in comets: toward the determination of the deuterium/hydrogen ratio in methane. Astrophys. J. 582, 534-539 (2003)

H. Kawakita, J.-i. Watanabe, D. Kinoshita, M. Ishiguro, E. Nakamura, Saturated hydrocarbons in comet 153P/Ikeya-Zhang: ethane, methane, and monodeuterio-methane. Astrophys. J. 590, 573-578 (2003)

H. Kawakita, J.-i. Watanabe, R. Furusho, T. Fuse, D.C. Boice, Nuclear spin temperature and deuterium-tohydrogen ratio of methane in comet C/2001 Q4 (NEAT). Astrophys. J. Lett. 623, L49-L52 (2005)

L.P. Keller, S. Messenger, On the origins of gems grains: a reply. Geochim. Cosmochim. Acta 107, 341-344 (2013)

L.P. Keller, K.L. Thomas, D.S. McKay, Carbon in primitive interplanetary dust particles, in Analysis of Interplanetary Dust, ed. by M.E. Zolensky, T.L. Wilson, F.J.M. Rietmeijer, G.J. Flynn. AIP Conf. Proc. (Am. Inst. of Phys., New York, 1994), pp. 159-164

L.P. Keller, S. Messenger, G.J. Flynn, S. Clemett, S. Wirick, C. Jacobsen, The nature of molecular cloud material in interplanetary dust. Geochim. Cosmochim. Acta 68, 2577-2589 (2004)

J. Kissel, F.R. Krueger, The organic component in dust from comet halley as measured by the puma mass spectrometer on board VEGA 1. Nature 326, 755-760 (1987)

M. Kleine, S. Wyckoff, P.A. Wehinger, B.A. Peterson, The carbon isotope abundance ratio in comet Halley. Astrophys. J. 439, 1021-1033 (1995)

J.D. Kramers, M.A.G. Andreoli, M. Atanasova, G.A. Belyanin, D.L. Block, C. Franklyn, C. Harris, M. Lekgoathi, C.S. Montross, T. Ntsoane, V. Pischedda, P. Segonyane, K.S. Viljoen, J.E. Westraadt, Unique chemistry of a diamond-bearing pebble from the Libyan desert glass strewnfield, SW Egypt: evidence for a shocked comet fragment. Earth Planet. Sci. Lett. 382, 21-31 (2013)

D.L. Lambert, A.C. Danks, High-resolution spectra of $\mathrm{C}_{2}$ Swan bands from comet West 1976 VI. Astrophys. J. 268, 428-446 (1983)

W.D. Langer, T.E. Graedel, M.A. Frerking, P.B. Armentrout, Carbon and oxygen isotope fractionation in dense interstellar clouds. Astrophys. J. 27, 581-604 (1984)

M.E. Lawler, D.E. Brownlee, CHON as a component of dust from comet Halley. Nature 359, 810-812 (1992)

A. Lecacheux, N. Biver, J. Crovisier, D. Bockelée-Morvan, P. Baron, R.S. Booth, P. Encrenaz, H.-G. Florén, U. Frisk, Å. Hjalmarson, S. Kwok, K. Mattila, L. Nordh, M. Olberg, A.O.H. Olofsson, H. Rickman, A. Sandqvist, F. von Schèle, G. Serra, S. Torchinsky, K. Volk, A. Winnberg, Observations of water in comets with Odin. Astron. Astrophys. 402, 55-58 (2003)

J.-E. Lee, E.A. Bergin, J.R. Lyons, Oxygen isotope anomalies of the Sun and the original environment of the solar system. Meteorit. Planet. Sci. 43, 1351-1362 (2008)

D.C. Lis, D. Bockelée-Morvan, J. Boissier, J. Crovisier, N. Biver, S.B. Charnley, Hydrogen isocyanide in comet 73P/Schwassmann-Wachmann (Fragment B). Astrophys. J. 675, 931-936 (2008)

D.C. Lis, A. Wootten, M. Gerin, E. Roueff, Nitrogen isotopic fractionation in interstellar ammonia. Astrophys. J. 710, L49-L52 (2010)

D.C. Lis, N. Biver, D. Bockelée-Morvan, P. Hartogh, E.A. Bergin, G.A. Blake, J. Crovisier, M. de Val-Borro, E. Jehin, M. Küppers, J. Manfroid, R. Moreno, M. Rengel, S. Szutowicz, A Herschel study of D/H in water in the Jupiter-Family comet 45P/Honda-Mrkos-Pajdusakova and prospects for D/H measurements with CCAT. Astrophys. J. 774, L3 (2013) 
K.E. Mandt, J.H. Waite, W. Lewis et al., Isotopic evolution of the major constituents of Titan's atmosphere based on Cassini data. Planet. Space Sci. 57, 1917-1930 (2009)

K. Mandt, O. Mousis, B. Marty, T. Cavalié, W. Harris, P. Hartogh, K. Willacy, Constraints from comets on the formation and volatile acquisition of the planets and satellites. Space Sci. Rev. (2015, this issue)

J. Manfroid, E. Jehin, D. Hutsemékers, A. Cochran, J.-M. Zucconi, C. Arpigny, R. Schulz, J.A. Stüwe, Isotopic abundance of nitrogen and carbon in distant comets. Astron. Astrophys. 432, 5-8 (2005)

J. Manfroid, E. Jehin, D. Hutsemékers, A. Cochran, J.-M. Zucconi, C. Arpigny, R. Schulz, J.A. Stüwe, I. Ilyin, The CN isotopic ratios in comets. Astron. Astrophys. 503, 613-624 (2009)

J.G. Mangum, R.L. Plambeck, A. Wootten, Fossil DCN in Orion-KL. Astrophys. J. 369, 169-174 (1991)

R.E. March, J.F.J. Todd, Quadrupole Ion Trap Mass Spectrometry (Wiley, New York, 2005)

B. Marty, The origins and concentrations of water, carbon, nitrogen and noble gases on Earth. Earth Planet. Sci. Lett. 313, 56-66 (2012)

B. Marty, R.L. Palma, R.O. Pepin, L. Zimmermann, D.J. Schlutter, P.G. Burnard, A.J. Westphal, C.J. Snead, S. Bajt, R.H. Becker, J.E. Simones, Helium and neon abundances and compositions in cometary matter. Science 319(5859), 75-78 (2008)

B. Marty, M. Chaussidon, R.C. Wiens, A.J.G. Jurewicz, D.S. Burnett, A ${ }^{15} \mathrm{~N}$-poor isotopic composition for the solar system as shown by genesis solar wind samples. Science 332, 1533-1536 (2011)

J.E.P. Matzel, H.A. Ishii, D. Joswiak, I.D. Hutcheon, J.P. Bradley, D. Brownlee, P.K. Weber, N. Teslich, G. Matrajt, K.D. McKeegan, G.J. MacPherson, Constraints on the formation age of cometary material from the NASA stardust mission. Science 328(5977), 483-486 (2010)

K.D. McKeegan et al., Isotopic compositions of cometary matter returned by stardust. Science 314, 17241728 (2006)

H.Y. McSween Jr., P.R. Weissman, Cosmochemical implications of the physical processing of cometary nuclei. Geochim. Cosmochim. Acta 53, 3263-3271 (1989)

R. Meier, T.C. Owen, H.E. Matthews, D.C. Jewitt, D. Bockelée-Morvan, N. Biver, J. Crovisier, D. Gautier, A determination of the $\mathrm{HDO} / \mathrm{H}_{2} \mathrm{O}$ ratio in comet C/1995 O1 (Hale-Bopp). Science 279, 842-844 (1998a)

R. Meier, T.C. Owen, D.C. Jewitt, H. Matthews, M. Senay, N. Biver, D. Bockelée-Morvan, J. Crovisier, D. Gautier, Deuterium in comet C/1995 O1 (Hale-Bopp): detection of DCN. Science 279, 1707-1710 (1998b)

R. Meier, D. Wellnitz, S.J. Kim, M.F. A'Hearn, The NH and CH bands of comet C/1996 B2 (Hyakutake). Icarus 136, 268-279 (1998c)

S. Messenger, Identification of molecular-cloud material in interplanetary dust particles. Nature 404, 968-971 (2000)

S. Messenger, L.P. Keller, F.J. Stadermann, R.M. Walker, E. Zinner, Samples of stars beyond the solar system: silicate grains in interplanetary dust. Science 300(5616), 105-108 (2003)

S. Messenger, L.P. Keller, D.S. Lauretta, Supernova olivine from cometary dust. Science 309(5735), 737-741 (2005)

S.N. Milam, S.B. Charnley, Observations of nitrogen fractionation in prestellar cores: nitriles tracing interstellar chemistry. Technical report. Lunar and Planetary Institute Science Conference Abstracts vol. 43, p. 2618 (2012)

S.N. Milam, C. Savage, M.A. Brewster, L.M. Ziurys, S. Wyckoff, The ${ }^{12} \mathrm{C} /{ }^{13} \mathrm{C}$ isotope gradient derived from millimeter transitions of $\mathrm{CN}$ : the case for galactic chemical evolution. Astrophys. J. 634, 1126$1132(2005)$

T.J. Millar, A. Bennett, E. Herbst, Deuterium fractionation in dense interstellar clouds. Astrophys. J. 340, 906-920 (1989)

Y.C. Minh, W.M. Irvine, D. McGonagle, L.M. Ziurys, Observations of the $\mathrm{H}_{2} \mathrm{~S}$ toward OMC-1. Astrophys. J. 360, 136-141 (1990)

O. Mousis, D. Gautier, D. Bockelée-Morvan, F. Robert, B. Dubrulle, A. Drouart, Constraints on the formation of comets from D/H ratios measured in $\mathrm{H}_{2} \mathrm{O}$ and $\mathrm{HCN}$. Icarus 148, 513-525 (2000)

T. Nakamura, T. Noguchi, Y. Ozono, T. Osawa, K. Nagao, Mineralogy of ultracarbonaceous large micrometeorites. Meteorit. Planet. Sci. Suppl. 40, 5046 (2005)

T. Nakamura, T. Noguchi, A. Tsuchiyama, T. Ushikubo, N.T. Kita, J.W. Valley, M.E. Zolensky, Y. Kakazu, K. Sakamoto, E. Mashio, K. Uesugi, T. Nakano, Chondrule-like objects in short-period comet 81P/Wild 2. Science 321, 1664-1667 (2008)

D. Nakashima, T. Ushikubo, D.J. Joswiak, D.E. Brownlee, G. Matrajt, M.K. Weisberg, M.E. Zolensky, N.T. Kita, Oxygen isotopes in crystalline silicates of comet Wild 2: a comparison of oxygen isotope systematics between Wild 2 particles and chondritic materials. Earth Planet. Sci. Lett. 357, 355-365 (2012)

D. Nakashima, T. Ushikubo, N.T. Kita, M.K. Weisberg, M.E. Zolensky, D.S. Ebel, Late formation of a comet Wild 2 crystalline silicate particle, Pyxie, inferred from Al-Mg chronology of plagioclase. Earth Planet. Sci. Lett. 410, 54-61 (2015) 
J. Neill, N.R. Crockett, E.A. Bergin, J.C. Pearson, L.-H. Xu, Deuterated molecules in Orion KL from Herschel/HIFI. Astrophys. J. 777, 85-104 (2013)

H.B. Niemann, S.K. Atreya, J.E. Demick, D. Gautier, J.A. Haberman, D.N. Harpold, W.T. Kasprzak, J.I. Lunine, T.C. Owen, F. Raulin, Composition of Titan's lower atmosphere and simple surface volatiles as measured by the Cassini-Huygens probe gas chromatograph mass spectrometer experiment. J. Geophys. Res., Planets 115, 12006 (2010)

A.O. Nier, D.J. Schlutter, The thermal history of interplanetry dust particles collected in the Earth's stratosphere. Meteoritics 28, 675-681 (1993)

T. Noguchi, N. Ohashi, S. Tsujimoto, T. Mitsunari, J.P. Bradley, T. Nakamura, S. Toh, T. Stephan, N. Iwata, N. Imae, Cometary dust in Antarctic ice and snow: past and present chondritic porous micrometeorites preserved on the Earth's surface. Earth Planet. Sci. Lett. 410, 1-11 (2015)

R.C. Ogliore, G.R. Huss, K. Nagashima, A.L. Butterworth, Z. Gainsforth, J. Stodolna, A.J. Westphal, D. Joswiak, T. Tyliszczak, Incorporation of a late-forming chondrule into Comet Wild 2. Astrophys. J. Lett. 745, L19 (2012)

T. Owen, The isotope ratio ${ }^{12} \mathrm{C} /{ }^{13} \mathrm{C}$ in comet Tago-Sato (1969g). Astrophys. J. 184, 33-44 (1973)

T. Owen, P.R. Mahaffy, H.B. Niemann, S. Atreya, M. Wong, Protosolar nitrogen. Astrophys. J. Lett. 553, L77 (2001)

L. Pagani, E. Roueff, P. Lesaffre, Ortho- $\mathrm{H}_{2}$ and the age of interstellar dark clouds. Astrophys. J. 739, L35L38 (2011)

B. Parise, C. Ceccarelli, A.G.G.M. Tielens, A. Castets, E. Caux, B. Lefloch, S. Maret, Testing grain surface chemistry: a survey of deuterated formaldehyde and methanol in low-mass class 0 protostars. Astron. Astrophys. 453, 949-958 (2006)

L. Piani, F. Robert, L. Remusat, Micron-scale D/H heterogeneity in chondrite matrices: a signature of the pristine solar system water? Earth Planet. Sci. Lett. 415, 154-164 (2015)

L. Remusat, F. Palhol, F. Robert, S. Derenne, C. France-Lanord, Enrichment of deuterium in insoluble organic matter from primitive meteorites: a solar system origin? Earth Planet. Sci. Lett. 243, 15-25 (2006)

L. Remusat, Y. Guan, Y. Wang, J.M. Eiler, Accretion and preservation of D-rich organic particles in carbonaceous chondrites: evidence for important transport in the early solar system nebula. Astrophys. J. 713(2), 1048-1058 (2010)

H. Roberts, G.A. Fuller, T.J. Millar, J. Hatchell, J.V. Buckle, Molecular D/H ratios in the dense gas surrounding low-mass protostars. Planet. Space Sci. 50, 1173-1178 (2002)

H. Roberts, E. Herbst, T.J. Millar, Enhanced deuterium fractionation in dense interstellar cores resulting from multiply deuterated $\mathrm{H}_{3}^{+}$. Astrophys. J. 591, L41-L44 (2003)

S.D. Rodgers, S.B. Charnley, Nitrogen isotopic fractionation of interstellar nitriles. Astrophys. J. 689, 14481455 (2008)

E. Roueff, J.C. Loison, K.M. Hickson, Isotopic fractionation of carbon, deuterium, and nitrogen: a full chemical study. Astron. Astrophys. 576, A99 (2015), 18 pp.

P. Rousselot, E. Jehin, J. Manfroid, D. Hutsemékers, The ${ }^{12} \mathrm{C}_{2} /{ }^{12} \mathrm{C}^{13} \mathrm{C}$ isotopic ratio in comets C/2001 Q4 (NEAT) and C/2002 T7 (LINEAR). Astron. Astrophys. 545, A24-A30 (2012)

P. Rousselot et al., Toward a unique nitrogen isotopic ratio in cometary ices. Astrophys. J. 780, L17-L21 (2014)

M. Rubin, K. Altwegg, H. Balsiger et al., Molecular nitrogen in comet 67P/Churyumov-Gerasimenko indicates a low formation temperature. Science 348, 232-235 (2015)

J. Santrock, S.A. Studley, J.M. Hayes, Isotopic analyses based on the mass spectrum of carbon dioxide. Anal. Chem. 57, 1444-1448 (1985)

B. SchläPpi et al., Influence of spacecraft outgassing on the exploration of tenuous atmospheres with in situ mass spectrometry. J. Geophys. Res. Space Phys. 115, 12313 (2010)

R.Y. Shah, H. Wootten, Deuterated ammonia in galactic protostellar cores. Astrophys. J. 554, 933-947 (2001)

Y. Shinnaka, H. Kawakita, H. Kobayashi, E. Jehin, J. Manfroid, D. Hutsemékers, C. Arpigny, Astrophys. J. 729, 81-95 (2011)

Y. Shinnaka, H. Kawakita, M. Nagashima, K. Hitomi, A. Decock, E. Jehin, D.C. Boice, High-dispersion spectroscopic observations of comet C/2012 S1 (ISON) with the Subaru telescope. AAS/Division for Planetary Sciences Meeting Abstracts 46, \#209.14 (2014a)

Y. Shinnaka, H. Kawakita, H. Kobayashi, M. Nagashima, D.C. Boice, ${ }^{14} \mathrm{NH}_{2} /{ }^{15} \mathrm{NH}_{2}$ ratio in comet C/2012 S1 (ISON) observed during its outburst in 2013 November. Astrophys. J. 782, L16-L19 (2014b)

S.B. Simon, D.J. Joswiak, H.A. Ishii, J.P. Bradley, M. Chi, L. Grossman, J. Aléon, D.E. Brownlee, S. Fallon, I.D. Hutcheon, G. Matrajt, K.D. McKeegan, A refractory inclusion returned by Stardust from comet 81P/Wild 2. Meteorit. Planet. Sci. 43, 1861-1877 (2008)

G. Slodzian, T.-D. Wu, N. Bardin, J. Duprat, C. Engrand, J.-L. Guerquin-Kern, Simultaneous hydrogen and heavier element isotopic ratio images with a scanning submicron ion probe and mass resolved polyatomic ions. Microsc. Microanal. 20, 577-581 (2013) 
F.J. Stadermann, P. Hoppe, C. Floss, P.R. Heck, F. Horz, J. Huth, A.T. Kearsley, J. Leitner, K.K. Marhas, K.D. McKeegan, T. Stephan, Stardust in stardust - the C, N, and O isotopic compositions of Wild 2 cometary matter in al foil impacts. Meteorit. Planet. Sci. 43(1-2), 299-313 (2008)

N.A. Starkey, I.A. Franchi, Insight into the silicate and organic reservoirs of the comet forming region. Geochim. Cosmochim. Acta 105, 73-91 (2013)

N.A. Starkey, I.A. Franchi, M.R. Lee, Isotopic diversity in interplanetary dust particles and preservation of extreme ${ }^{16}$ O-depletion. Geochim. Cosmochim. Acta 142, 115-131 (2014)

A. Stawikowski, J.L. Greenstein, The isotope ratio ${ }^{12} \mathrm{C} /{ }^{13} \mathrm{C}$ in a comet. Astrophys. J. 140, 1280-1291 (1964)

V. Taquet, S.B. Charnley, O. Sipilä, Multilayer formation and evaporation of deuterated ices in prestellar and protostellar cores. Astrophys. J. 791, 1-20 (2014)

P.P. Tennekes, J. Harju, M. Juvela, L.V. Tóth, HCN and HNC mapping of the protostellar core ChamaeleonMMS1. Astron. Astrophys. 456, 1037-1043 (2006)

R. Terzieva, E. Herbst, The possibility of nitrogen isotopic fractionation in interstellar clouds. Mon. Not. R. Astron. Soc. 317, 563-568 (2000)

K.L. Thomas, G.E. Blanford, L.P. Keller, W. Klöck, D. McKay, Carbon abundance and silicate mineralogy of anhydrous interplanetary dust particles. Geochim. Cosmochim. Acta 57, 1551-1566 (1993)

B.E. Turner, Detection of doubly deuterated interstellar formaldehyde $\left(\mathrm{D}_{2} \mathrm{CO}\right)$ — an indicator of active grain surface chemistry. Astrophys. J. 362, L29-L33 (1990)

B.E. Turner, Deuterated molecules in translucent and dark clouds. Astrophys. J. Suppl. Ser. 136, 579-629 (2001)

H.C. Urey, Origin of tektites. Nature 179, 556-557 (1957)

V. Vanysek, in Comets, Asteroids, Meteorites: Interrelations, Evolution and Origins, ed. by A.H. Delsemme. IAU Colloq., vol. 39 (1977), p. 499

G.L. Villanueva, M.J. Mumma, B.P. Bonev, M.A. Di Santi, E.L. Gibb, H. Böhnhardt, M. Lippi, A sensitive search for deuterated water in comet 8p/Tuttle. Astrophys. J. 690, L5-L9 (2009)

J.H. Waite Jr. et al., Liquid water on Enceladus from observations of ammonia and ${ }^{40} \mathrm{Ar}$ in the plume. Nature 460, 487-490 (2009)

K.J. Walsh, A. Morbidelli, S.N. Raymond, D.P. O'Brien, A.M. Mandell, A low mass for Mars from Jupiter's early gas-driven migration. Nature 475, 206-209 (2011)

S.F. Wampfler, J.K. Jorgensen, M. Bizzarro, S.E. Bisschop, Observations of nitrogen isotope fractionation in deeply embedded protostars. Astron. Astrophys. 20, 577-581 (2014)

W.D. Watson, V.G. Anicich, W.T. Huntress Jr., Measurement and significance of the equilibrium reaction ${ }^{13} \mathrm{C}^{+}+{ }^{12} \mathrm{CO} \rightleftharpoons{ }^{12} \mathrm{C}^{+}+{ }^{13} \mathrm{CO}$ for alteration of the ${ }^{13} \mathrm{C} /{ }^{12} \mathrm{C}$ ratio in interstellar molecules. Astrophys. J. 205, L165-L168 (1976)

H.A. Weaver, M.F. A'Hearn, C. Arpigny, M.R. Combi, P.D. Feldman, G.-P. Tozzi, N. Dello Russo, M.C. Festou, Atomic Deuterium Emission and the D/H Ratio in Comets. LPI Contributions, vol. 1405 (2008), p. 8216

M.K. Weisberg, H.C. Connolly, On the relationship between chondrites, comets, and asteroids, a petrologic perspective, in Lunar Planet. Sci., vol. XXXIX (2008)

K. Willacy, A.C. Alexander, M. Ali-Dib, S.B. Ceccarelli Charnley, M. Doronin, Y. Ellinger, P. Gast, E. Gibb, S.N. Milam, O. Mousis, F. Pauzat, C. Tornow, E.S. Wirström, E. Zicler, Space Science Reviews (2015). this volume

E.S. Wirström, W.D. Geppert, Å. Hjalmarson, C.M. Persson, J.H. Black, P. Bergman, T.J. Millar, M. Hamberg, E. Vigren, Observational tests of interstellar methanol formation. Astron. Astrophys. 533, 24-34 (2011)

E.S. Wirström, S.B. Charnley, M.A. Cordiner, S.N. Milam, Isotopic anomalies in primitive solar system matter: spin-state-dependent fractionation of nitrogen and deuterium in interstellar clouds. Astrophys. J. 757, L11-L15 (2012)

D.H. Wooden, Cometary refractory grains: interstellar and nebular sources. Space Sci. Rev. 138, 75-108 (2008)

P.M. Woods, K. Willacy, Carbon isotope fractionation in protoplanetary disks. Astrophys. J. 693, 1360-1378 (2009)

A. Wootten, ALMA capabilities for observations of spectral line emission. Astrophys. Space Sci. 313, 9-12 (2008)

I.P. Wright, S.J. Barber, G.H. Morgan, A.D. Morse, S. Sheridan, D.J. Andrews, J. Maynard, D. Yau, S.T. Evans, M.R. Leese, J.C. Zarnecki, B.J. Kent, N.R. Waltham, M.S. Whalley, S. Heys, D.L. Drummond, R.L. Edeson, E.C. Sawyer, R.F. Turner, C.T. Pillinger, Ptolemy-an instrument to measure stable isotopic ratios of key volatiles on a cometary nucleus. Space Sci. Rev. 128, 363-381 (2007)

S. Wyckoff, P. Wehinger, Chemical abundance of comets, in Reports of Planetary Astronomy (1988), pp. 145-146 
S. Wyckoff, E. Lindholm, P.A. Wehinger, B.A. Peterson, J.-M. Zucconi, M.C. Festou, The C-12/C-13 abundance ratio in comet Halley. Astrophys. J. 339, 488-500 (1989)

S. Wyckoff, M. Kleine, B.A. Peterson, P.A. Wehinger, L.M. Ziurys, Carbon isotope abundances in comets. Astrophys. J. 535, 991-999 (2000)

L. Yang, F.J. Ciesla, C.M.O. Alexander, The D/H ratio of water in the solar nebula during its formation and evolution. Icarus 226, 256-267 (2013)

H. Yurimoto, K. Kuramoto, Molecular cloud origin for the oxygen isotope heterogeneity in the solar system. Science 305, 1763-1766 (2004)

L.M. Ziurys, C. Savage, M.A. Brewster, A.J. Apponi, T.C. Pesch, S. Wyckoff, Cyanide chemistry in comet Hale-Bopp (C/1995 O1). Astrophys. J. 527, L67-L71 (1999) 